DA-2001, núms. 259-260. JOSÉ TUDELA ARANDA. La ley y el reglamento en el Derecho del turis...

José Tudela Aranda

Doctor en Derecho.

Letrado Mayor de las Cortes de Aragón

\title{
La ley y el reglamento en el Derecho del turismo
}

SUMARIO: I. UNAS REFLEXIONES NECESARIAS PERO INSUFICIENTES SOBRE LA LEY Y EL REGLAMENTO COMO FUENTES DEL DERECHO. 1. UNA APROXIMACIÓN A LA TEORÍA DE LA LEY EN LA CONSTITUCIÓN. LA IDEA DE RESERVA DE LEY. 2. LA POTES'TAD REGLAMENTARIA. EL ÁMBITO DEL REGLAMENTO INDEPENDIENTE. 3. ALGUNA CONSIDERACIÓN SOBRE UNOS CAMBIOS NO TAN LEJANOS. II. EL DERECHO Y EL TURISMO. LA TRADICIONAL REGULACIÓN REGLAMENTARIA DEL TURISMO. 1. CONSIDERACIONES GENERALES SOBRE LA RELACION ENTRE DERECHO Y TURISMO. 2. CAUSAS Y CONSECUENCIAS DEL DOMINIO DEL REGLAMENTO EN LA ORDENACIÓN JURÍDICA DEL TURISMO. III. LA IDONEIDAD DE LA LEY PARA REGULAR CON CARÁCTER GENERAL EL TURISMO. 1. LOS PRESUPUESTOS DEL DEBATE. 2. RAZONES QUE AVALAN LA IDONEIDAD DE LA LEY COMO NORMA GENERAL PARA LA REGULACIÓN DEL TURISMO. 3. ALGUNA REFLEXIÓN A LA LUZ Y A LA SOMBRA DE LAS LEYES APROBADAS. IV. LA POTESTAD REGLAMENTARIA EN EL ACTUAL DERECHO DEL TURISMO. ALGUNAS CUESTIONES CONTROVERTIDAS. 1. EL ÁMBITO NA'TURAL DEL REGLAMENTO EN LA ORDENACION DEL TURISMO. LA COLABORACIÓN LEY/REGLAMENTO. 2. LA PROBLEMÁTICA RELACIONADA CON LA RESERVA DE LEY. V. A MODO DE CONCLUSIÓN.

\section{UNAS REFLEXIONES NECESARIAS PERO INSUFICIENTES SOBRE LA LEY Y EL REGLAMENTO COMO FUENTES DEL DERECHO}

\section{UNA APROXIMACIÓN A LA TEORÍA DE LA LEY EN LA CONSTITUCION. LA IDEA DE RESERVA DE LEY}

Es del todo ocioso señalar que el estudio de la ley, de su consideración en sí misma como fuente del Derecho, de su posición en el orde- 
namiento y, por tanto, de su relación con el reglamento, es una de las cuestiones centrales del Derecho público, del Derecho en general. Una cuestión de extraordinaria relevancia porque nos acerca a alguno de los temas centrales de todo ordenamiento. Su relación con el poder, la posición del ciudadano como sujeto de derechos y obligaciones, la legitimidad del ordenamiento, su propia eficacia, son sólo alguna de las cuestiones que gravitan alrededor del examen de esta fuente primigenia del Derecho.

No tan ocioso puede resultar recordar la especial importancia que esta cuestión tiene en el Derecho español, fundamentalmente por los débitos que nuestro ordenamiento posee en relación con una teoría general de la ley y por las peculiaridades heredadas de un régimen político radicalmente distinto al constitucional ${ }^{1}$. Sin duda, es una de las grandes cuestiones pendientes. Pronto la mejor doctrina reclamó atención preferente sobre esta cuestión ${ }^{2}$, sobre una cuestión que, se señalaba, presentaba una dificultad innegable. Desde esos primeros estudios, el diagnóstico inicial sobre su complejidad no sólo se ha confirmado sino que, puede decirse, se ha mostrado con una intensidad incluso superior a las previsiones iniciales. Factores como el extraordinario desarrollo del Estado autonómico, la incorporación a la Unión Europea o los intensos cambios tecnológicos y sociales acaecidos desde entonces,

1 Como señalaba recienternente el profesor SANTAMARÍA, son notables los rasgos de nuestro actual ordenamiento que tienen su raíz en el del régimen del General Franco, cuando no se trata de puras similitudes (vid. J.A. SANTAMARIA PASTOR, «El sistema de fuentes del derecho en los primeros cincuenta años de vida de la "Revista de Administración Pública" (1950-1999)", $R A P \mathrm{n}^{\circ} 150,1999$, pp. 542 y ss.). No puede extrañar que este hecho distorsione lo que sería una consideración unormal» de la teoría de la ley y de la potestad reglamentaria en un régimen democrático.

2 Recuérdense en este punto las tempranas palabras del profesor RUBIO LLORENTE: "La jurisprudencia, y en especial, la jurisprudencia conscitucional, no podrá llevar a cabo su tarea, sin embargo, si no es apoyada en una teoria de la ley cutya construcción es en este momento, quizá el mayor reto dirigido a los juristas españoles» [F. RUBIO LLORENTE, «Rango de ley, fuerza de ley, valor de ley (sobre el problema del concepto de ley en la Constitución)», $R A P \mathrm{n}^{\circ} 100-102$, 1983, p. 432]. La teoría de la ley y su posición en el ordenamiento que nacía fruto de un nuevo orden político mereció la consideración de gran parte de la más significativa doctrina. Sin hacer referencia a estudios más concretos, y además del citado del profesor RUBIO LLORENTE, pueden citarse: F. RUBIO LLORENTE, «El procedimiento legislativo en España. El lugar de la ley entre las fuentes del Derecho», $R E D C \mathrm{n}^{\circ} 16,1986$, pp. 83-113; E. GARCla DE ENTERRIA y T.R. FERNÁNDEZ, Curso de derecho administrativo vol. I, pp. 103-165, 8a edición, 1997; E. GARCIA DE ENTERRIA, Reflexiones sobre la Ley y los principios generales del Derecho, Civitas, 1984; J.A. Santamaría PASTOR, Fundamentos de derecho administrativo, 1988, pp. 513553; A. Garrorena, El litgar de la ley en la Constitución española, Tecnos, 1980; I. de OTTO PARDo, Derecho constitucional. Sistema de fuentes, Ariel, 1987, pp. 102-181; J. PÉREZ RoYo, Las fuentes del derecho, Tecnos, 1985, pp. 81-95; L.M. DIEZ-PICAZO, «Concepto de ley y tipos de leyes (¿Existe una noción unitaria de ley en la Constitución española? )», $R E D C \mathrm{n}^{\circ} 24,1988$, pp. 47-93; F. de CARRERAS, «La ley en el constitucionalismo y en la Constitución española», RFDUC, número homenaje al Profesor D. Luis Sánchez Agesta, 1989, pp. 287-318. 
han contribuido a convertir en una misión casi imposible el desiderátum del profesor RUBIO LLORENTE. Ahora bien, la innegable dificultad del empeño no debiera hacer desistir de, al menos, aproximarse a esta tarea y con ello a todas las cuestiones que gravitan alrededor de la misma.

Sin duda, se trata de una tarea muy alejada de las pretensiones de estas páginas. De unas páginas que sólo buscan acercar al lector a las peculiaridades de un sector del ordenamiento, el encargado de normar el Derecho del turismo, desde el análisis de la presencia de la ley y el reglamento en el mismo. Ahora bien, realizar el estudio concreto de las mismas en relación con el Derecho del turismo exige como premisa inexcusable realizar unas consideraciones generales, siquiera breves y forzosamente limitadas, sobre la ley y, en su momento, sobre la potestad reglamentaria.

En relación con la ley, son diversas las cuestiones relativas a su teoría general que son de forzosa consideración a la hora de enjuiciar su presencia en el Derecho del turismo. Claramente, la cuestión central es aquella vinculada con el concepto de reserva de ley, con la complejidad que este concepto posee en nuestro ordenamiento.

Pero antes de traer a colación los principales razonamientos doctrinales en relación con tan espinosa cuestión, bueno será que recordemos la razón de ser de la ley como fuente primigenia del Derecho en el sistema constitucional, es decir, su vinculación directa con la idea de legitimación democrática ${ }^{3}$. No es vano recordar en este punto, siguiendo al profesor GARCÍA DE ENTERRÍA, que la democracia postula inexorablemente una determinada organización del Derecho y de sus instituciones centrales y que la ley, como expresión de la democracia, aunque no sea el único instrumento de organización social es, hoy por hoy, insustituible 4 . Y es que el estudio de la ley en el Derecho del turismo no podrá prescindir de esta premisa. Como se verá inmediatamente, esta vinculación a la idea democrática es fundamental para comprender el juego de la reserva de ley. Pero no finaliza aquí la importancia para nuestro trabajo de esta reflexión. El papel que a la ley se atribuye en estas páginas se encuentra firmemente vinculado a la convicción de que la regulación esencial de un sector de tanta importancia y complejidad como el turismo no puede ser ajeno a la única fuente del Derecho vinculada en su esencia al principio democrático. No se olvidan, como se

${ }^{3}$ El estudio de la ley como fuente del Derecho directamente vinculada al principio y sistema democrático es algo casi tan antiguo como el propio concepto de ley. En consecuencia, las referencias bibliográficas son numerosísimas. Citamos aquí por todos uno de los últimos trabajos del profesor GARCIA DE ENTERRÍA: E. GARCIA DE ENTERRÍA, «La democracia y el lugar de la ley", en El derecho, la Ley y el Juez, E. GARCía DE ENTERRÍA y A. MENENDEZ MENÉNDEZ, Civitas, 1997, pp. 23-66.

${ }^{4}$ Vid. E. GARCÍA DE ENTERRfA, «La democracia y ...», ob. cit., p. 50. 
subrayará en su momento, los matices y dificultades que plantea en el presente la relación entre ley y democracia, las insuficiencias de unas formas y procedimientos que pueden llegar a hacer pensar que una afirmación como la antedicha se aproxima a la más pura retórica. Pero nada de ello es, ni será, obstáculo para mantener la idea fundamental. Es decir, que la regulación de un sector fundamental de la acción pública debe proyección directa del principio democrático. Y que hoy por hoy no hay otro instrumento normativo para cumplir esta tarea que no sea la ley.

Fue la consideración de la ley como expresión de la voluntad popular, su ligazón estrecha e inmediata con el principio democrático, lo que dio fundamento al nacimiento del concepto de reserva de ley. La necesidad de vincular a la voluntad popular la regulación de determinadas materias obligaba a reservar las mismas a la ley como norma emanada del Parlamento. En consecuencia, sólo el legislador podría modificar aquellas materias que previamente se hubiesen regulado por ley. Los conceptos de reserva de ley formal y material se instalaban en el ordenamiento constitucional llamados a tener una posición central en el mismo. Una posición que han ocupado hasta nuestros días en los que siguen siendo referencia inexcusable a la hora de tratar el sistema de fuentes.

Pero la vigencia de la posición de este concepto en la teoría y en la práctica dista mucho de significar que no existan problemas alrededor del mismo. Por el contrario, casi puede afirmarse que mucho de lo que sugiere este concepto es hoy problemático ${ }^{5}$. Una problemática compleja, de alcance transcendente y, desde luego, alejada de la vocación y posibilidades de estas páginas. Una problemática directamente ligada a la gran dificultad que en el presente plantea la indeterminación del concepto de ley. Como subrayó el profesor RUBIO LLORENTE 6 , sólo cuando se sabe lo que es la ley puede atribuirse un significado concreto a los preceptos constitucionales que reservan a la ley determinadas cuestiones y pueden resolverse los muchos problemas concretos que suscita la habilitación que el legislador concede a la Administración para regular por vía de reglamento determinadas materias. Y hoy, en nuestro ordenamiento, resulta extraordinariamente complejo definir con precisión el concepto de ley. Muchos son los factores que han coadyuvado a esta situación. No son ajenos los cambios sociales y formales acaecidos desde la aprobación del texto constitucional. Pero el problema de la definición de la ley tiene entre nosotros raíz en los propios preceptos

${ }^{5}$ En realidad, como tuvo ocasión de subrayar el profesor S. MARTín-RETORTILLO, el principio de reserva de ley fue siempre cuestión polémica y cargada de un inequívoco alcance político (vid. S. MARTIN-RETORTILLO BAQUER, Derecho administrativo económico, vol I, La Ley, 1988, p. 158).

${ }^{6}$ Véase F. RUBio LLORENTE, «Rango de ley, fuerza de ley...», ob. cit., p.418. 
DA-2001, núms. 259-260. JOSÉ TUDELA ARANDA. La ley y el reglamento en el Derecho del turis...

constitucionales. La multiplicidad de tipos legales que se derivan de los mismos, las interrogantes que plantea la idea de fuerza de ley, la fragmentación territorial y orgánica de las fuentes de producción, son sólo algunas de las circunstancias que han hecho hasta ahora imposible la formulación en nuestro Derecho de una teoría general de la ley. Todo ello es causa fundamental del progresivo debilitamiento de este concepto, de los intentos por reducir su alcance ${ }^{7}$.

Sin embargo, es un concepto imprescindible. Su vinculación al principio de legitimación democrática del ordenamiento lo hace, mientras no se alcance a diseñar fórmulas alternativas, del todo necesario para el correcto desarrollo de los valores constitucionales. De esta irrenunciabilidad se derivan, y no paradójicamente, con toda su fuerza, los muchos y significativos problemas que para el operador jurídico plantea este concepto. Problemas que, hay que decir, y como se procurará precisar a lo largo de estas páginas, se agravan con el sistema de fuentes derivado de la distribución territorial del poder político y del notable significado alcanzado entre nosotros por la autonomía política. ¿Cuáles son exactamente las materias afectadas por el principio de reserva de ley? ¿Cómo juega este principio en la relación cruzada entre la Constitución y los Estatutos de Autonomía? ¿Cuál es el alcance del mismo? ¿Cualquier regulación de una materia reservada a la ley debe ser vedada a la potestad reglamentaria? Todo ello ha provocado que ni la doctrina ni nuestra práctica jurídica hayan dado una respuesta unilateral a las cuestiones planteadas. Así, se ha señalado, el principio de reserva de ley es susceptible en nuestro Derecho de numerosas matizaciones, pudiendo incluso distinguirse, según las expresiones utilizadas por el texto constitucional, entre reserva absoluta, reserva reforzada y reserva relativa ${ }^{8}$.

Como habrá de verse, todos éstos son problemas presentes con singular fuerza en el Derecho del turismo. No puede ser de otra manera en una materia que tradicionalmente ha sido campo abonado casi en exclusiva para la potestad reglamentaria. Cuando después de casi veinte años de aprobada la Constitución las Comunidades Autónomas han comenzado a aprobar leyes generales de ordenación del sector turístico, se han puesto en evidencia las dificultades que numerosas normas reglamentarias, muchas de ellas aún vigentes, plantean por su roce sino

7 Situación brillantemente descrita por el profesor S. MARTín-RETORTILLO, que destacaba los esfuerzos por desdibujar su alcance, reducir su operatividad y abuso de interpretaciones sesgadas (vid. S. MARTíN-RETORTILLO BAQUER, Derecho adninistrativo económico, ob. cit., p. 158).

${ }^{8}$ Sobre este particular, véase S. MAR'TíN-RETOR'TILlo BAQUER, Derecho administrativo económico, ob. cit., pp. 160 y ss.; en general, sobre la reserva de ley, L. VILLACORTA MANCEBO, Reserva de ley y Constitución, Dykinson, 1994, quien rechaza la distinción entre reserva absoluta y reserva relativa, p. 36. 
afección directa con materias que se encuentran constitucionalmente reservadas a la ley. No será posible resolver radicalmente todas las cuestiones que se suscitan. No lo será porque para ello tendría que tenerse una respuesta clara a los problemas de teoría general de fuentes suscitados. Pero sí parece necesario plantear las dudas más relevantes e intentar acercar alguna vía de solución. Soluciones que, forzosamente, habrán de estar ligadas a aquellos principios que fundamentan el confepto y significado de la ley y que, en consecuencia, dictan el lugar que corresponde al reglamento.

Será en el estudio concreto de la presencia de la ley en el Derecho del turismo cuando se examinen más detenidamente alguna de las cuestiones planteadas. Lógicamente, se hará desde las premisas aquí expuestas. Desde la complejidad de la ley como fuente del Derecho en el ordenamiento jurídico español y desde su rotunda e indisoluble vinculación al principio democrático. Será esta última una cuestión de especial importancia en nuestro análisis. Se estudiará la relación general que la ley puede mantener con la ordenación de la acción turística desde la profunda convicción de que hablar de ley es hablar de política. Es ésta una dimensión que en ocasiones parece olvidada y que se me antoja crucial para comprender el exacto papel de cada fuente de producción del Derecho. Como inmediatamente se hará notar, el estudio del sistema de fuentes, su revisión a la luz de los profundos cambios políticos, sociales, económicos y hasta tecnológicos acaecidos en los últimos años es tarea pendiente, quizá la de mayor calado que ha de abordarse desde la teoría jurídico pública. Pues bien, en su realización, la primera premisa que debiera cumplirse es partir de la raíz de cada una de las fuentes del Derecho. Por ello, el estudio de la ley deberá realizarse en paralelo al análisis de la consideración que merece lo político como fuente de producción del Derecho. Ello puede parecer evidente. Puede parecer hasta un recordatorio innecesario. Pero sinceramente lo considero preciso. Cuando el legislador, estatal o autonómico, regula por ley casi cualquier materia, cuando el lenguaje de la inmensa mayoría de los textos legales se acerca más al de las reglamentaciones técnicas que al de la expresión política, cuando el ciudadano es ajeno a los textos aprobados, cuando éstos no aciertan a traducir su vocación transformadora, cuando lo expuesto es sólo una pequeña parte de la pobreza simbólica en la que ha decaído la ley, entonces parece preciso realizar la advertencia antedicha ${ }^{9}$.

${ }^{9}$ Por la importancia de estas reflexiones introductorias habrá lugar para volver siquiera brevemente sobre las mismas. La progresiva desvinculación de la ley de sus caracteres más netamente políticos es, sin duda, una de las cuestiones centrales de la crisis de esta institución. Es difícil saber si este alejamiento es sólo consecuencia de otras circunstancias reiteradamente citadas por la doctrina (véase, por todos, J.A. SANTAMARf́a PASTOR, Fundamentos de derecho 
DA-2001, núms. 259-260. JOSÉ TUDELA ARANDA. La ley y el reglamento en el Derecho del turis...

En cualquier caso, aquí se estudiará la ley como fuente del Derecho en directa conexión con esa caracterización política que se le atribuye. Estas páginas pretenderán, además, dejar constancia de la utilidad que el estudio del Derecho del turismo, por sus propias y peculiares características, puede tener para la reflexión general que necesita nuestro Derecho público. En pocos sectores de la intervención administrativa podrán observarse con mayor claridad y desde normas más recientes la complejidad de valores e intereses a los que ese Derecho público ha de dar respuesta y la complejidad de los instrumentos dedicados a esa finalidad ${ }^{10}$.

\section{LA POTESTAD REGLAMENTARIA. EL ÁMBITO DEL REGLAMENTO INDEPENDIENTE}

La potestad reglamentaria, es decir, la capacidad de las Administraciones públicas de producir normas jurídicas, es una de las cuestiones más relevantes del Derecho público. Muy por encima de los posibles y justificados recelos provocados por la entrega al poder público de un arma de tan considerables dimensiones, se ha impuesto su consolidación desde la unánime aceptación de su necesidad. Una necesidad que el Estado social sólo ha incrementado, hasta el punto de hacer añorables los tiempos en los que Carl Schmitt habló de legislación motorizada u Ortega y Gasset de legislación incontinente. Desde aquellos años, 1946 y 1953, respectivamente, la producción normativa de las administraciones públicas no ha dejado de crecer. Ha crecido el número de nor-

administrativo, ob. cit., pp. 532-542) o si, por el contrario, es en este alejamiento donde éste el origen de toda la crisis. Así, sin duda, la fuerza atribuida a la Constitución es uno de los factores que ha contribuido, como habrá de verse un poco más despacio, poderosamente, al alejamiento de la ley de la política. Ahora bien, deste alejamiento se produce por la propia fuerza del concepto de Constitución que desplaza inconscientemente a la ley a terrenos más administrativos? o ¿la propia debilidad política del concepto de ley es un factor esencial para el crecimiento de la fuerza normativa del texto constitucional, con independencia de que, lógicamente, a medida que éste ha crecido la debilidad de la ley se haya acrecentado?

10 En efecto, una de las grandes virtudes que el Derecho del turismo ofrece al estudioso es precisamente la actualidad de muchas de las cuestiones que en él se suscitan, cuestiones que perfectamente serían generalizables. La presencia simultánea, en ocasiones de muy dificil diferenciación, de elementos de Derecho público y elementos de Derecho privado, la novedad de las técnicas organizativas utilizadas, los propios problemas planteados alrededor del sistema de fuentes, la multiplicidad de valores, a veces difícilmente conciliables, a los que se pretende servir, son algunas de las cuestiones que revalorizan el estudio del Derecho del turismo. Sin duda que hay otros sectores de la acción administrativa que plantean y quizá hasta con mayor claridad la insuficiencia de conceptos y teoría clásicas, al menos en sus interpretaciones hasta ahora vigentes. Sectores de gran complejidad tecnológica, con necesidades peculiares y diversas a las que tradicionalmente ha tenido que satisfacer el Derecho administrativo, pueden plantear también interrogantes como los que se atribuía al Derecho del turismo. Pero en pocos de estos sectores las cuestiones se plantearán con la intensidad con la que sucede en el Derecho del turismo. 
mas y ha crecido el número de sectores de la acción administrativa objeto de atención por parte del legislador administrativo. De esta forma, el estudio de la potestad reglamentaria no puede detenerse en la conveniencia de su existencia. Es un estudio abocado a examinar la justificación que soporta semejante poder ${ }^{11}$. Tampoco son estas páginas dedicadas a glosar esta forma de producción normativa. Pero, de nuevo, existe la obligación de, siquiera someramente, acercarse a alguna de las cuestiones fundamentales planteadas por la misma, al objeto de poder comprender con acierto su papel, por lo demás de extraordinaria relevancia, en el complejo mundo del Derecho del turismo.

En efecto, el reglamento ha sido una fuente de singular importancia en el Derecho del turismo ${ }^{12}$. Importancia que llega hasta el extremo, como habrá de verse más detenidamente en páginas posteriores, de monopolizar en la práctica la regulación de este sector de la acción administrativa. En este punto, debe quedar constancia de cómo esa transcendencia se vincula a la propia razón de ser de la potestad reglamentaria. Si la justificación última de la potestad reglamentaria es la necesidad ineludible que tiene la Administración de contar con un instrumento normativo que le permita intervenir en la ordenación de las relaciones de los particulares con el poder de manera ágil y eficaz, su abundante presencia en el mundo del turismo, sin cobertura legal en la mayor parte de las ocasiones, se deberá a la necesidad que la Administración tenía de ordenar un sector de tanta significación económica ${ }^{13}$.

Es precisamente el dato de la abundancia de normas reglamentarias sin previa ley general el que aboca el presente estudio al examen de una de las cuestiones más debatidas de la teoría general de la potestad reglamentaria. Me refiero, claro esta, a la problemática planteada por el concepto de reglamento independiente. De alguna manera, la otra cara

11 En este sentido, A. EMBid Irujo, «Potestad reglamentaria», RVAP n 29, 1991, p. 74.

12 El carácter fundamentalmente economicista con el que los poderes públicos se han enfrentado tradicionalmente a la actividad turística ha sido, como habrá ocasión de analizar posteriormente, circunstancia fundamental para esta posición dominante del reglamento. Este enfoque no es exclusivo de nuestro país. Así, Pierre PY, estudia el Derecho del turismo en Francia desde su consideración de una rama del Derecho administrativo económico y con un enfoque básicamente economicista (P. PY, Droit du toutrisme, Dalloz, París, $4^{\circ}$ ed., 1996). Sobre la presencia del reglamento en el Derecho administrativo económico, S. MARTíN-RETORTILlo BAQUER, Derecho administrativo económico, ob. cit., pp.162 y ss.

13 El protagonismo del Gobierno y de la Administración en la acción económica y, por ende, la abundancia de normas reglamentarias en estas materias tiene, a juicio del profesor S. MARTÍN-RETORTILLO, causa en las peculiares características que objetivamente tiene la realidad económica: carácter coyuntural de muchas de las medidas a adoptar, urgencia de las mismas, contenido eminentemente técnico de muchas de ellas. Situación que habrá que conciliar con las exigencias constitucionales en relación con el principio de legalidad (Vid. S. MARTín-RetorTIllo BAQUer, Derecho administrativo económico, ob. cit., p.159). 
de la moneda de la ya examinada reserva de ley. El estudio del reglamento independiente es relevante para el Derecho del turismo. Lo ha sido históricamente porque durante muchos años el reglamento ha sido la única norma utilizada, y muy abundantemente, en la ordenación del turismo y lo es en la actualidad porque su importancia no ha decaído con la reciente aprobación de numerosas leyes generales del turismo por las Comunidades Autónomas. El día a día sigue demostrando la vigencia del debate que plantea esta modalidad reglamentaria en el sector del ordenamiento que se examina. Por ello, es preciso detenerse brevemente en las consideraciones que sobre este particular ha realizado nuestra doctrina.

La cuestión debatida es si en nuestro ordenamiento tiene cabida o no el reglamento independiente, es decir, el reglamento que se dicta sin que lo autorice una ley previa. De esta forma, y de ahí la importancia de la cuestión, lo que se está discutiendo son los límites constitucionales del poder de la Administración ${ }^{14}$. Dadas las limitaciones de estas páginas, y siguiendo por todos al profesor BAN̆O LEÓN, se pueden resumir las posiciones de nuestra doctrina al respecto en tres. En primer lugar, aquellos que reducen el ámbito del reglamento independiente a la esfera interna de la Administración ${ }^{15}$; en segundo lugar, aquellos que admitirían el reglamento independiente en todas aquellas materias no específicamente reservadas a la ley por la Constitución ${ }^{16}$; en tercer lugar, y finalmente, aquellos que, aun admitiendo la existencia del reglamento independiente, lo restringen a aquellas materias que no afecten ni a las reservas específicas de la ley ni al principio general de reserva que excluye que el reglamento sin autorización pueda afectar a las materias que atañen a la libertad de acción de los particulares ${ }^{17}$.

$\mathrm{Si}$ bien puede decirse que en líneas generales la tercera de las tesis expuestas, al menos en sus rasgos definitorios, es la tesis mayoritaria en la doctrina y jurisprudencia, también hay que decir que ni el parecer

14 Vid. J.M. BAÑO LEÓN, «Los ámbitos del reglamento independiente» en Estudios sobre la Constiutuión española. Homenaje al profesor Eduardo García de Enterria, tomo I, Civitas, 1991, p. 421. En general, sobre el tema del reglamento independiente, del mismo autor, Los límites constitucionales de la potestad reglamentaria (remisión normativa y reglamento independiente en la Constitución de 1978), Civitas, 1991.

15 Véase E. Garcla de ENTERRÍa y T.R. Fernández, Curso de Derecho administrativo, vol. I, p. 227, $8^{\text {a }}$ edición, 1997.

16 Vid. A. Gallego Anaibitarte y A. Menéndez ReXaCh, «Comentario al artículo 97», en Óscar AlZAGA (dir.), La Constitución española de 1978, tomo VIII, pp. 81-82.

17 En este sentido, J. A. SANTAMaría PASTOR, Fundamentos de Derecho administrativo, ob. cit., pp. 776-783. Es también la tesis de J.M. BAÑO LEON, «Los ámbitos del reglamento independiente...n, ob. cit., p. 424. 
doctrinal y jurisprudencial es unánime al respecto y que la propia Administración sigue pautas muy divergentes. Se trata, pues, de una cuestión esencialmente abierta. Y quizá no pueda ser de otra manera por las propias dificultades de acotar con claridad sus términos en una sociedad tan compleja y cambiante como la actual. En efecto, la cuestión no se reduce a discutir la mera posibilidad de la existencia o no de esa norma de procedencia administrativa sin la previa habilitación legal. La cuestión se torna realmente compleja cuando se entra en los posibles ámbitos de afección del reglamento independiente y, sobre todo, en sus límites materiales, ya en la inmediatez de la problemática planteada por la reserva de ley. Y si como se ha visto es esa una cuestión sin resolver entre nosotros no otra cosa sucede en relación con la eventual posibilidad de aprobar reglamentos independientes. De hecho, sólo resolviendo con claridad la posición de la ley en nuestro sistema de fuentes puede darse respuesta precisa a la posición de la potestad reglamentaria y con ella al reglamento independiente ${ }^{18}$.

En cualquier caso, parece preciso señalar que las consideraciones realizadas en relación con la ley son igualmente válidas a la hora de enjuiciar el alcance y significado de la potestad reglamentaria. En efecto, el análisis de la misma deberá realizarse desde la búsqueda de aquellos rasgos que hoy le son o debieran ser más significativos. En este sentido, cabría apuntar que la procedencia del reglamento de un órgano administrativo, es decir, su origen administrativo no parece hoy por hoy su rasgo más definitorio. La diferente relación que el Estado de partidos plantea entre los poderes ejecutivo y legislativo obliga a reconsiderar el origen de la norma como elemento definitorio fundamental. Parece necesario plantearse desde las nuevas circunstancias, desde su descripción real y no puramente teórica, cuál es el papel que en relación con la producción de normas corresponde al poder ejecutivo y, con él, a la Administración. Parece obligado entrar a examinar con detenimiento cuál debe ser el contenido de las normas aprobadas por la Administración. Quizá sólo cuando se haya avanzado en estas cuestiones sea posible dar soluciones más contundentes a la cuestión suscitada por el reglamento independiente, cuestiones que, como se observará, se ponen de relieve en toda su extensión en el Derecho del turismo. En estas páginas se contrastará la realidad de este sector del ordenamiento con las posiciones doctrinales y jurisprudenciales mayoritarias. Pero no se renunciará a señalar cómo de nuevo el Derecho del turismo contribuye a poner en evidencia alguna de las cuestiones más significativas de teoría general.

${ }^{18}$ En este punto es importante hacer notar la posición claramente contraria a la admisión de los reglamentos independientes en el ámbito económico de una significativa parte de nuestra doctrina (por todos, S. MARTÍN-RETORTILlO BAQUER, Derecho administrativo económico, ob. cit., p 163). 
Así, al objeto de hacer más gráficas alguna de las consideraciones anteriores se pueden plantear algunos interrogantes en relación con materias cercanas al Derecho del turismo, interrogantes a los que se procurará dar contestación en páginas posteriores pero que bien pueden servir para hacerse una idea de la importancia de las dudas planteadas. ¿'Todos los derechos citados en el Título I de la Constitución estarían afectados por la reserva de ley? ${ }^{19}$. En su caso, desta afección sería radical o habría espacio para la posible regulación por normativa reglamentaria independiente de algunas cuestiones? Así, ¿es en cualquier caso necesario una ley para regular las agencias de viaje en virtud de la libertad de empresa? ¿'Sólo por ley deben regularse los precios de los establecimientos turísticos o el derecho de admisión? Estas y otras muchas cuestiones están detrás de las dudas generales planteadas por el alcance que en la materia turística puede tener la potestad reglamentaria. En esta materia se pone de relieve con toda claridad la dificultad que supone dar rango de ley a normas que por su relación con materias objeto de reserva de ley bien podrían ser reguladas por esta fuente del Derecho, pero que por su contenido, técnico, de escasa dimensión política, coyuntural, se ajustan mal a las características generales de la ley como fuente del Derecho.

Son sólo unas pequeñas muestras de las muchas cuestiones concretas en las que se traducen estas dudas iniciales. A lo largo de estas páginas se examinarán con detenimiento porque el examen de la posición de la ley y el reglamento en el Derecho del turismo tiene que intentar dar alguna respuesta a las mismas. Pero será siempre una respuesta necesariamente dubitativa, condicionada por la indeterminación general en las que se mueven en nuestro Derecho el ámbito de la reserva de ley y la existencia y alcance del reglamento independiente. El convencimiento de la necesidad de detenerse en esta problemática y no olvidar las importantes mutaciones sociales acaecidas nos lleva a una breve reflexión antes de comenzar el examen particularizado de estas fuentes en el Derecho del turismo.

\section{ALGUNA CONSIDERACIÓN SOBRE UNOS CAMBIOS NO TAN LEJANOS}

En el discurrir de las líneas que anteceden se ha querido significar que la problemática que las fuentes del Derecho plantean en relación

19 En relación con esta cuestión el profesor BAÑo se muestra tajante al señalar que cuando el reglamento limita esferas de la libertad de los privados, al afectar derechos fundamentales como la libertad de empresa, la propiedad, al incidir en esferas sometidas a la reserva constitucional como el comercio interior, la existencia de ley previa es irrenunciable (J.M. BAÑo LEÓN, «Los ámbitos del reglamento independiente...», ob. cit., p. 447). 
con el Derecho del turismo no es algo estrictamente circunscrito a esta materia. Se piensa, y por ello se ha considerado preciso anticiparlo, que la rica y muy diversa problemática planteada es hoy fiel reflejo de las dificultades en las que se mueven conceptos tradicionales y hondamente arraigados, conceptos de extraordinaria importancia, seguramente válidos en lo que significan pero que con la misma seguridad requieren de nuevos planteamientos en relación con su funcionalidad y acomodación a las nuevas circunstancias sociales y políticas. Por ello, una cuestión que en el contexto de un estudio tradicional del sistema de fuentes tenía ya importantes peculiaridades, se presenta ahora como una cuestión central. En efecto, el dominio casi absoluto del reglamento, la importancia y significación de alguna de las materias reguladas por esta fuente, rozando cuando menos los límites clásicos de la reserva de ley, eran ya cuestiones de importancia. Cuestiones a las que el estudio de la historia del Derecho de nuestro turismo debiera responder en su momento. Pero hoy, como se intentará poner de relieve a lo largo de estas páginas, las cuestiones planteadas desbordan ese tratamiento. Ya no se trata sólo de explicar el papel del reglamento o de intentar determinar si unos reglamentos determinados vulneran o no la reserva de ley. Habrá que dar un paso más. Habrá que contrastar las dudas planteadas por las normas turísticas con los datos más relevantes derivados de la innegable crisis del sistema tradicional de fuentes. Y habrá que intentar alimentar el debate sobre ese sistema de fuentes desde esas mismas dudas.

Las páginas que preceden han querido situar al lector, en la seguridad de su insuficiencia pero con la convicción de su necesidad, ante una esquemática descripción de las principales cuestiones con las que habrá de enfrentarse el estudio concreto de las fuentes del Derecho del turismo ${ }^{20}$. Como ya ha quedado reflejado, pocas respuestas contundentes podrán esperarse. Más bien parece camino abierto a los interrogantes, a las dudas, invitación permanente a la reflexión. No es, desde luego, que hasta que no haya elaborada una teoría general de la ley no se pueda discurrir siquiera sea por aproximación sobre las fuentes del Derecho del turismo. Pero sí habrá de dejar constancia de la debilidad de la aproximación. Y habrá de ser así porque las dudas que hoy suscita la posición de la ley en nuestıo ordenamiento no son dudas que se circunscriban a pequeños matices más o menos significativos. Esas dudas son hoy de mucha mayor transcendencia. El estudio de la posición de esta fuente del Derecho en relación con la acción administrativa en materia de turismo contribuirá poderosamente a reiterarse en esa afirmación.

${ }^{20}$ Cuando se alude a modo de generalización a las fuentes del Derecho del turismo, se es plenamente consciente que éstas no son únicamente la ley y el reglamento, únicas fuentes que van a ser estudiadas en el presente trabajo. En cualquier caso, la importancia y significación de otras fuentes en relación con esta actividad administrativa es muy sscasa. 
Éste puede ser el lugar adecuado para introducir una reflexión añadida antes de comenzar a estudiar aspectos más concretos de nuestro trabajo. Puede avanzarse que algunas de las cuestiones que se suscitan en el estudio de la ley y el reglamento en el turismo sirven para apoyar la idea de que la debilidad de la adecuación de la formulación teórica de nuestro sistema de fuentes a su propia realidad, sus dificultades para acometer con eficacia las exigencias derivadas de un notable cambio social y tecnológico, son tales que se hace del todo preciso plantearse como tarea prioritaria su análisis y eventual corrección. La ley no puede resistir durante mucho tiempo, y con la dignidad debida a su fuente de legitimación, textos como la mayoría de los derivados del Derecho comunitario, proclamas que nada norman o cambios inmediatos que hacen difícil llegar a su texto completo y vigente. La ley no puede seguir siendo esa norma forzada entre las obligaciones derivadas de nuestra pertenencia a la Unión Europea y las necesidades muchas veces artificiales de producción normativa, especialmente en algunas Comunidades Autónomas. La ley no puede seguir siendo una norma en gran medida oculta por la fuerza normativa de la Constitución. La ley no puede seguir siendo cada día un poco más desconocida para los ciudadanos ${ }^{21}$. Seguramente, muchas de las cuestiones planteadas son de difícil solución con las formas tradicionales de la ley. Por ello, seguramente, habría que plantearse una revisión en profundidad y no meros retoques más o menos significativos.

Las reflexiones suscitadas por el estudio del reglamento no son muy diversas en cuanto a la metodología. La posición actual del poder ejecutivo, su indudable legitimidad democrática, la muy creciente necesidad de normas que respondan sin excesivos límites a la complejidad técnica de muchas materias, a la necesidad de modificar con frecuencia aspectos concretos de la misma, a las exigencias del Derecho comunitario o a la conveniencia de pactar con la sociedad civil aspectos principales de la misma son, entre otras, algunas de las cuestiones que obligan a reconsiderar la posición del reglamento en el sistema de fuentes y su relación con la ley.

No puede separarse el estudio de estas dos cuestiones. El estudio diferenciado de las mismas sólo ha de entenderse como una cuestión metodológica. El problema planteado es único. En un régimen político como el actual, en un Estado que cada día tiene más condicionado su Derecho por el ordenamiento comunitario, en un orden social cada vez más complejo y mutante, cómo pueden responder las fuentes del Derecho al reto simultáneo del mantenimiento de los valores que las legiti-

21 Es evidente que cada una de las reflexiones realizadas sobre la difícil realidad de la ley en nuestro sistema social, sobre todo si no olvidamos como marco comparativo las grandes palabras de su teoría general, requerirían de una explicación detenida. El alcance de estas páginas nos impide adentrarnos en semejante tarea. Sólo se ha querido significar con unas breves notas el alcance de una crisis que transciende con mucho la inquietud de los juristas. 
man y de su eficacia. Por ello, se exige una respuesta unitaria. Desde estas páginas se intentará ir poniendo de relieve aquellas características del sistema de fuentes del Derecho del turismo que más directamente se vinculan a esta problemática.

\section{EL DERECHO Y EL TURISMO. LA TRADICIONAL REGULACIÓN REGLAMENTARIA DEL TURISMO}

\section{CONSIDERACIONES GENERALES SOBRE LA RELACIÓN ENTRE DERECHO Y TURISMO}

La relación entre la actividad turística y el Derecho tiene una serie de peculiaridades a las que parece preciso referirse para entender cabalmente la posición de las distintas fuentes, y en concreto del reglamento, en el Derecho del turismo. Desde el principio, cabe decir que la primera y principal paradoja en la relación entre el Derecho y el turismo es la fuerte diferencia que se percibe entre la realidad y una aproximación superficial que se ha podido considerar mayoritaria hasta la fecha. En efecto, hasta fechas muy recientes la relación entre el Derecho y el turismo ha sido una relación casi inexistente para la doctrina ${ }^{22}$. La sensación dominante es que la actividad turística era una actividad exclusivamente económica y que las normas existentes para regular la misma eran escasas, fragmentarias y de muy escaso interés doctrinal.

22 A este particular me he referido en otra publicación, haciendo constar los escasos trabajos dedicados por la doctrina al Derecho del turismo (J. TUDELA ARANDA, «La Administración turística", $\operatorname{RarAP} \mathbf{n}^{\circ} 15,1999$, pp. 93-94). Sin duda, esta cuestión ha cambiado radicalmente en los dos últimos o tres años. En este tiempo los trabajos doctrinales se han multiplicado. Entre los publicados pueden citarse los volúmenes colectivos: Estudios sobre el régimen jurídico del turismo, coordinado por J. TUDELA ARANDA, Diputación Provincial de Huesca, 1997; Ttrismo. Organización administrativa, calidad de servicios y competitividad empresarial, coordinado por D. BlanQuer CRIADO, Tirant lo Blanch-Diputación Provincial de Castellón, Valencia, 1999; Régimen jurtídico de los recursos tutrísticos, RArAP, Monográfico III, 1999, coordinado por J. TUDELA ARANDA; Lecciones del Derecho del turismo, Tirant lo Blanch, 2000, dirigido por R GARCíA-MACHO y A. RECALDE CASTELLS y coordinado por M.V. PETIT LAVALL La monografia: Derecho del Tutrismo, D. BLANQuer CrIADO, Tirant lo Blanch, Valencia 1999. Y los artículos: J. Tudela ARANDA, «Hacia un nuevo régimen jurídico del turismo: la reciente legislación autonómica», $R V A P \mathrm{n}^{\circ} 45-\mathrm{I}$, pp. 291 y ss.; J. TUDELA ARANDA, "La Administración turística», ob. cit.; J.M. SOCías CAMACHO, «Evolución de la legislación turística en las Islas Balearesm, RArAP $\mathrm{n}^{\circ} 13,1998$, pp. 197-236; J. FERREIRA y A NOGUEIRA, «Turismo y ambiente: legislación autonómica y nuevas técnicas para un desarrollo sostenible», RArAP 13, 1998 pp. 341-378; A. SALGADO CASTRO, «La distribución de competencias en materia de turismom, RArAP $\mathrm{n}^{\circ}$ 9, 1996; F.J. BLANCO HERRANZ, «Descentralización y cooperación interadministrativa en el turismo español. Proceso, instrumentos y propuestas de futuro", Estudiar Turisticos n 137,1998 , pp. 67-86. No es arriesgado señalar que la aprobación de un grupo numeroso de leyes generales de ordenación de la actividad turística por las Comunidades $\mathrm{Au}$ tónomas y la rica problemática en ellas suscitadas ha contribuido a este interés doctrinal. 
DA-2001, núms. 259-260. JOSÉ TUDELA ARANDA. La ley y el reglamento en el Derecho del turis...

Sin embargo, con sólo una somera aproximación histórica al Derecho del turismo puede observarse que ello no ha sido nunca así. La presencia normativa en la actividad turística ha sido intensa, abundante y afectando cuestiones de indudable interés doctrinal. Lo que sí ha sido, desde luego, es un terreno ajeno a la ley. Las leyes aprobadas en esta materia han sido muy escasas y puede decirse que hasta la aprobación en 1994 de la Ley general de ordenación del turismo del País Vasco, han sido leyes organizativas o competenciales ${ }^{23}$. Pero esta ajenidad de la ley en absoluto ha significado que el turismo estuviese escasamente normado. Al revés, el turismo es un sector en el que la acción administrativa ha sido intensa y abundante. $Y$ como no podía ser de otra manera desde esta premisa, abundante e intensa ha sido también la utilización de normas de alcance y significado muy diverso.

El examen histórico demuestra que el turismo es uno de los sectores que más tempranamente llama a la Administración a intervenir. Su importancia económica es percibida con prontitud y desde 1905, cuando por Real Decreto de 6 de octubre se crea la Comisión Nacional para el Fomento del Turismo, se plantea abiertamente la necesidad de una política pública de intervención en el sector ${ }^{24}$. Si bien esa política va a estar fundamentalmente restringida al ámbito de la policía y el fomento, no por ello dejan de existir algunas normas curiosas y significativas por lo que tienen de ejemplo de la siempre mayor proyección que el turismo ha tenido en nuestras Administraciones públicas. Sin duda, la década de 1960 abre una nueva etapa para el turismo español ${ }^{25}$. Sin em-

23 Deben recordarse en este punto los decretos organizativos aprobadas antes de la guerra civil y las leyes competenciales aprobadas ya en la década esplendorosa del turismo español. Pueden citarse como más destacadas la Ley $48 / 1963$, de 8 de julio, de competencia en materia turística y la Ley 197/1963, de 28 de diciembre, de Centros y Zonas de Interés Turístico Nacional. Un detenido estudio de la legislación turística preconstitucional puede verse en: R. GARCía MACHO, «La legislación turística: naturaleza jurídica; relaciones entre Derecho estatal, autonómico y local en Lecciones de Derecho del turismo», ob. cit., pp. 20-25.

${ }^{24}$ Por su elocuencia merece la pena transcribir algunos párrafos de la Exposición de Motivos del Real Decreto de 6 de octubre de 1905: «Señor. Entre los medios eficaces que las naciones emplean para mantener su riqueza en creciente desarrollo y para lograr que su moneda tenga un valor legal efectivo, hay que poner en primer término el mantenimiento de una balanza económica favorable, de una balanza en la cual los ingresos de todo género sean mayores que los gastos. Esos ingresos de la balanza económica de las naciones no se forman exclusivamente de las mercancías que se exportan: tienen, por cl contrario, otras muchas fuentes, y entre ellas, se encuentra la creciente aficion a viajar, que constituye en el extranjero un deporte de todas las clases sociales y, especialmente, de las más acomodadas... Función propia de la iniciativa privada debe ser aquí, como lo ha sido en otras naciones, impulsar y desarrollar el turismo. Pero ante la falta de acción social, el Estado se cree en el deber de dar ejemplo y de estimular a todos en la tarea patribtica de fomentar las incursiones de extranjeros en nutestra patria».

25 ministrativa, puede verse, J. TUDELA ARANDA «La Administración turística», ob. cit., pp. 98-105. 
bargo, los cambios normativos son escasamente cualitativos. Puede señalarse que el cambio más notable es la importancia dada a los aspectos competenciales. La necesidad de promover al máximo el crecimiento de un sector que se planteaba como una fuente extraordinaria de ingresos y desarrollo ${ }^{26}$ puso de relieve la necesidad de concentrar todas aquellas decisiones que afectasen al sector en la Administración central, en concreto en el Ministerio de Información y Turismo ${ }^{27}$. Junto a este aspecto competencial se multiplicaron las normas de fomento y policía, convirtiendo el Derecho del turismo en un marasmo de normas de muy difícil integración por la inexistencia de textos legislativos de mayor ambición. Ello, junto a la vocación puramente economicista de toda la acción pública en la materia, fue sin duda, el factor fundamental que alejó a la doctrina española del estudio de estas normas. Y esta ausencia de elementos doctrinales sirvió para seguir alimentando la sensación de extrañeza entre el turismo y el Derecho.

Esta situación no cambia con el nuevo régimen político ni con la correspondiente aprobación del texto constitucional. En la Constitución no hay referencias sustanciales al turismo. Sólo la obligada a la hora de establecer el reparto de competencias entre Estado y Comunidades Autónomas ${ }^{28}$ introduce el término turismo en nuestra norma fundamental. El hecho de que el turismo sea una de las primeras competencias asumidas efectivamente por las Comunidades Autónomas no produjo, paradójicamente, una reflexión sobre esta materia. En aquellas Comunidades en las que el turismo tenía una significativa importancia económica, nada se alteró mientras los resultados económicos no estuvieron en peligro. En aquellas Comunidades en las que el turismo era una actividad menor desde el punto de vista económico, siguió manteniendo una condición marginal y residual. En consecuencia, la producción normativa de las Comunidades Autónomas en una materia sobre la que tenían competencia exclusiva era en 1994 escasa y limitada a la aprobación de aquellas normas reglamentarias que se hacían imprescindibles por la antigüedad de muchas normas estatales y a la aprobación de las leyes llamadas a satisfacer el principio de legalidad en materia de Derecho sancionador.

${ }^{26}$ Sobre el turismo en esta época y desde una perspectiva económica, véase la clásica obra del profesor J. CALS, Turismo y política uturistica en España: una aproximación, Ariel, 1974.

27 Ésta es la auténtica finalidad de las citadas leyes 48/1963, de 8 de julio, de competencia en materia turística y la Ley 197/1963, de 28 de diciembre, de Centros y Zonas de Interés Turístico Nacional.

${ }^{28}$ En relación con la significación del texto constitucional para la política turística y correspondientemente para sus normas reguladoras puede verse J. TUDELA ARANDA, «Hacia un nuevo régimen jurídico del turismo..., ob. ob. cit. 
DA-2001, núms. 259-260. JOSÉ TUDELA ARANDA. La ley y el reglamento en el Derecho del turis...

La fecha que marca el nacimiento de una nueva etapa es 1994, por ser, como ya se ha dicho, el año en el que se aprueba la primera ley general de ordenación de la actividad turística. Desde entonces, y hasta hoy, se han aprobado otras once leyes ${ }^{29}$. No parece preciso insistir en la importancia que para el Derecho del turismo supone la existencia de estas normas. Es fácilmente constatable que desde su aprobación comienza a poder hablarse del estudio del Derecho del turismo. Y, desde luego, esa fecha será de indudable interés para el estudio del reglamento. No sólo porque, evidentemente, desde entonces su protagonismo decaerá considerablemente. También porque la aparición de la ley como una norma con vocación de regulación totalizadora, la aparición de unas normas dotadas de una indudable impronta política, va a obligar a plantearse cuál es el papel que corresponde en la nueva situación al reglamento y cuál debe ser su relación con esas leyes aprobadas.

De esta esquemática descripción se deduce que el Derecho ha estado presente, incluso con intensidad, en el turismo. Una intervención qué puede pensarse inevitable por la indubitable transcendencia del turismo sobre la economía española. El poder público no podía permanecer ajeno a este sector y en su intervención debía acudir al Derecho. Ahora bien, como ya se ha señalado, es precisamente esa visión economicista del turismo, una visión vigente hasta fechas muy recientes, la que se encuentra en la raíz del dominio histórico del reglamento. En efecto, cuando el poder público ha comprendido que en la actividad turística no sólo pueden tenerse como referencia los logros económicos, cuando se ha comprendido la necesidad de equilibrar la política turística con las exigencias medioambientales, cuando se ha comprendido la utilidad del turismo como instrumento de ordenación del territorio o como revitalizador del patrimonio histórico, cuando se ha comprendido la necesidad de convertir a la calidad en referencia básica

29 En realidad son doce, ya que en la Comunidad Autónoma de Madrid se han aprobado dos, derogándose el primer texto. Son las siguientes leyes: Ley 6/1994, de 16 de marzo, de la Comunidad Autónoma del País Vasco, de ordenación del turismo; Ley 7/1995, de 6 de abril, de la Comunidad Autónoma de Canarias, de ordenación del turismo; Ley 1/1999, de 12 de marzo, de ordenación del turismo, de la Comunidad Autónoma de Madrid que deroga la Ley de 4 de abril de 1995, de ordenación del turismo; Ley 2/1997, de 20 de marzo, de la Comunidad Autónoma de Extremadura, de turismo; Ley 9/1997, de 21 de agosto, de la Comunidad Autónoma de Galicia, de ordenación y promoción del turismo; Ley 11/1997, de 12 de diciembre, de la Comunidad Autónoma de Murcia, de turismo; Ley 10/1997, de 19 de diciembre, de la Comunidad Autónoma de Castilla y León, de turismo; Ley 3/1998, de 21 de mayo, de la Comunidad Valenciana, de turismo; Ley 2/1999, de 24 de marzo, general turística de las Islas Baleares; Ley 5/1999, de 24 de marzo, de ordenación del turismo, de Cantabria; Ley 8/1999, de 26 de mayo, de ordenación del turismo, de Castilla-La Mancha; Ley 12/1999, de 15 de diciembre, del turismo, de Andalucía. No sería de extrañar que en la presente legislatura se aprueben normas similares en las mayoría de las cinco Comunidades Autónomas en las que todavía no se ha aprobado (Cataluña, Navarra, Rioja, Aragón y Asturias). Al menos en dos de ellas se están ya elaborando los correspondientes anteproyectos. 
de la nueva política turística, haciendo, en consecuencia, de la protección del turista como consumidor y usuario principio fundamenta ${ }^{30}$, es entonces cuando el poder ha acudido a la ley como instrumento regulador del Derecho del turismo y cuando su estudio ha suscitado mayor interés. Si algo caracteriza al moderno Derecho del turismo es que entiende la actividad turística de manera polifuncional, es decir, que son diversos los fines a los que se las vincula ${ }^{31}$. Es en este cambio, en esta mayor ambición de la política turística, donde ha surgido el espacio para la ley.

Si de nuevo acudimos al pasado en la relación entre el Derecho y el turismo, habrá de advertirse cómo de esa dimensión estrictamente economicista se ha derivado una consecuencia significativa, el carácter casi siempre técnico, administrativo, coyuntural, sin apenas vocación de permanencia ni de generalidad del Derecho que ha normado el turismo. Circunstancias todas estas, como se verá, estrechamente ligadas a ese dominio del reglamento.

En cualquier caso, la reciente aprobación de las leyes por las Comunidades Autónomas no debe llamar a engaño. Podría pensarse que su aprobación deriva del convencimiento de la importancia del Derecho como instrumento de articulación de la nueva política turística. Desde luego, como se ha indicado, estas normas han abierto una nueva etapa en la relación entre el Derecho y el turismo. Pero más bien parece que esa etapa se ha abierto para la doctrina. Es difíil tener el convencimiento de que para el poder público ha sucedido algo parecido, incluso en aquellas Comunidades Autónomas que han aprobado esas leyes. Sigue existiendo la percepción de que el Derecho es un instrumento secundario en el desarrollo de la política turística. De hecho, los principales y más significativos documentos elaborados en los últimos años sobre la actividad turística apenas hacen precisiones sobre el papel que corresponde al Derecho en el desarrollo dela nueva política que se propugna ${ }^{32}$. Esta

${ }^{30}$ La introducción de estas consideraciones en la política turística es fruto del profundo cambio social acaecido en los últimos años, de un cambio que ha hecho al turista más exigente y más plural en sus gustos. Es en este cambio cuando puede apreciarse, siquiera sea de manera indirecta, la influencia de la Constitución en el Derecho del turismo postconstitucional.

31 Atribuir a la política turística fines en relación con la protección del medio ambiente o del patrimonio histórico o utilizarla como agente de la ordenación del territorio, no significa, ni mucho menos, que se haya perdido de vista su dimensión económica. Sin duda, esta consideración sigue siendo prevalente como no podía ser de otra manera en una actividad de tanta transcendencia para la economía del país. Lo que sucede es que el poder público ha entendido que el mantenimiento de esos réditos económicos está vinculado a una distinta manera de hacer y entender el turismo.

32 El Plan FUTURES, sin hacer una referencia siquiera mediana a los aspectos jurídicos de la política turística, al menos cita por primera vez esta cuestión como uno de los objetivos de Plan: «La adaptación del marco jurídico e institucional para la seguridad en la coma de decisiones empresariales y la mayor efectividad de las mismas. Ello es especialmente relevante cuando se acometen proyectos a medio y largo plazo, situación caracteristica en el proceso de redefinición del sector turistico en la actualidad (Plan Marco de Competitividad del Turismo Espa$\bar{n} o l$, Ministerio de Industria, Comercio y Turismo, Secretaría General de Turismo, Madrid, p. 63). Tampoco es mucho más explícito al respecto el, por lo demás, bastante exhaustivo informe resultante de la Ponencia del Senado para el estudio del sector turístico en España. 
percepción puede agudizarse si la impresión superficial sobre la escasa eficacia de los textos aprobados se comprobase fehacientemente ${ }^{33}$.

Si ya durante el régimen político anterior se postulaba la necesidad de elaborar un sistema integrador de las normas turísticas ${ }^{34}$, un sistema que las articulase en torno a unos valores que superasen los objetivos meramente económicos, hoy ese desiderátum se ha convertido en una exigencia inexcusable. Los intereses y materias afectados por la actividad turística son excesivamente importantes y complejos como para no tener ese sistema normativo que ayude al aplicador del Derecho a obtener del turismo todas sus virtualidades y a paliar sino eliminar sus eventuales afecciones. Así parece que se ha entendido cuando se ha procedido a aprobar alguno de los ambiciosos textos legales hoy vigentes. Pero la consecución de ese sistema jurídico no derivará por sí solo de la aprobación de esas normas. Es ésta una tarea que requerirá de la multiplicación de los estudios y de la elaboración de los correspondientes principios jurídicos que puedan contribuir a resolver las numerosas cuestiones conflictivas que han de suscitarse.

La tarea citada no es obra gratuita. No es el deseo artificial de los juristas. Difícilmente puede dudarse que el desarrollo de la nueva política turística, de esa política de calidad y objetivos múltiples, requiere entre otras cosas, pero no, desde luego en el último lugar, de una nueva relación entre el Derecho y el turismo. Porque cuando se alude a la suspicacia con la que se observa desde el turismo su relación con el Derecho, la cuestión planteada no es la del mayor o menor acierto o idoneidad del camino emprendido. En realidad, lo que está aún en el aire es el convencimiento sobre el hecho de convertir la actividad turística en algo más que en un mero instrumento de crecimiento económico. Si el compromiso con las premisas de la nueva política turística es cierto, inevitablemente llegará el convencimiento de la necesidad de acudir al Derecho como instrumento para desarrollar esa política. Los valores que se ligan a las nuevas formas del turismo son valores esenciales en nuestra sociedad, son valores que requieren del debate y análisis político. El Derecho no será así el cauce de ordenación técnica de aquellas cuestiones que precisen esa intervención. Dicho con puridad. Seguirá siendo eso. Pero será también mucho más. El Derecho cumplirá en relación con el turismo esa función de ordenación general, de traslación de la decisión y valoración política que desempeña tradicionalmente y

${ }^{33}$ Un dato sin duda significativo y preocupante y que refuerza los temores expresados es el muy escaso desarrollo reglamentario que han tenido las leyes aprobadas. Este dato puede hacer pensar en las dudas que suscitan al aplicador la nueva normativa aprobada.

34 Vid. J. FernándeZ Álvarez, Curso de Derecho administrativo turístico, Editora $\mathrm{Na}$ cional, 1974, p. 11. 
que no había desempeñado hasta la fecha en relación con el turismo. Es precisamente el hecho de que sea en términos de presente esta relación entre el turismo y el Derecho lo que permite comprender la significación que tiene la dimensión que se otorgue a la ley en términos formales y materiales. $Y$ es este hecho el que permitirá reflexionar sobre las exigencias que el sistema de fuentes tiene para acometer sus tareas tradicionales en la actualidad.

\section{CAUSAS Y CONSECUENCIAS DEL DOMINIO DEL REGLAMENTO EN LA ORDENACIÓN JURÍDICA DEL TURISMO}

Como se ha subrayado reiteradamente, el Derecho del turismo ha estado tradicionalmente dominado por la normativa reglamentaria. Esta situación es una constante desde la aparición de las primeras normas turísticas. Pero fue con el desarrollo turístico de la década de los sesenta cuando resultó más significativa. Por un lado, el número de normas se multiplicó atendiendo a los diversos y nuevos frentes que la Administración pretendía cubrir. Por otro, no dejaba de ser paradójico el hecho de que el reconocimiento por el poder de la transcendencia de la actividad turística no estuviese acompañado por una normación de rango y contenido más ambicioso. En cualquier caso, la abundancia de normas reglamentarias será una de las primeras cosas que llame la atención del estudioso del Derecho del turismo ${ }^{35}$. Por ello, es necesario reflexionar sobre las causas de esta circunstancia y las consecuencias que la misma ha provocado sobre ese Derecho y, en última instancia, sobre la actividad turística.

Para entender el papel otorgado al reglamento en el Derecho del turismo es preciso recordar la visión netamente economicista y fragmentaria que el poder público ha tenido de este sector de actividad económica. El turismo no ha sido visto hasta fechas muy recientes como una política pública ${ }^{36}$. El turismo era una actividad económica de gran transcendencia por sus repercusiones sobre las cifras de nuestra econo-

35 En este sentido, D. AZNAR JORDAN, «Disposiciones normativas en el ámbito turísticon en Estudios sobre el régimen jurídico del turismo, ob. cit., p. 169.

36 Seguramente tampoco en la actualidad puede entenderse como generalizada la visión del turismo como una política pública. Pero es innegable que en algunas Comunidades Autónomas el turismo ha merecido una reflexión general sobre el alcance y objetivos a alcanzar desde la actividad turística, objetivos que, obviamente, condicionan la perspectiva e intervención pública en la materia. La aprobación de leyes generalistas ha sido, sin duda y como habrá ocasión de ver, un hito significativo en la valoración del turismo como algo más que una gran industria. 
DA-2001, núms. 259-260. JOSÉ TUDELA ARANDA. La ley y el reglamento en el Derecho del turis...

mía. Una actividad que se incrementaba constantemente sin grandes alardes teóricos y sobre la que sólo se consideraba necesario intervenir para promover su crecimiento y establecer unas mínimas reglas de policía. En el fondo, todo eran medidas encaminadas a mantener las grandes cifras económicas. Desde esta consideración, no había lugar, excepto en materias muy concretas, a la aprobación de leyes, y el terreno estaba abonado para la proliferación de normas reglamentarias.

Es conocida, y así ha sido señalado por la mejor doctrina, la importancia que necesariamente posee el reglamento en el Derecho administrativo económico, por ser sus características más fácilmente adaptables a las exigencias de la realidad económica que las de la ley ${ }^{37}$. El casuismo que ofrece esa realidad, la dimensión estrictamente técnica de muchas de sus necesidades, la perentoriedad de la mayoría de las medidas a adoptar, la necesidad de poseer un instrumento dotado de flexibilidad para el cambio, son sólo alguna de las razones que justifican la privilegiada posición del reglamento en el Derecho administrativo económico. Razones, por otra parte, plenamente aplicables a la ordenación jurídica del turismo.

Junto a estas razones, predicables casi en relación con todos los sectores de la actividad económica, habría que preguntarse por razones específicas, por aquellas que puedan explicar lo verdaderamente peculiar del Derecho del turismo. Porque lo que sorprende en relación con la ordenación jurídica del turismo no es la abundancia de reglamentos. Lo que sorprende es la ausencia, al menos durante muchos años, de soporte legal para los mismos. A esta circunstancia hay que intentar dar respuesta, ya que ésta es la que hace verdaderamente singular la posición del reglamento en este sector del ordenamiento.

No parece equivocado insistir en el enfoque neta y exclusivamente económico que el poder dio al poder público como primera causa de que el protagonismo del reglamento en este sector llegase al extremo de obviarse la presencia de la ley. En el fondo, lo que latía no era sólo el monopolio de la perspectiva económica. Detrás estaba también la consideración de que no había ningún otro interés público afectado por la actividad turística. El poder podía regular por ley otros sectores económicos de la acción administrativa por la presencia en los mismos de intereses diversos muchas veces contrapuestos. Sin embargo, en,relación con el turismo se pensaba que el único objetivo era su crecimiento y que en él coincidía toda la sociedad. Para la consecución de este objetivo, el reglamento era una norma adecuada. El valor de la flexibilidad en la norma para su consecución fue consideración añadida. Por otro lado, no se consideraba necesario dar estabilidad a esa normativa. Se trataba de una legislación aprobada sin ninguna vocación de permanencia.

37 Vid. S. MARTín-Retortillo BAQUer, Derecho administrativo económico, ob. cit., pp. 167 y ss. 
De la circunstancia anterior deriva otra de indudable transcendencia para comprender la posición del reglamento. La falta de una visión institucional en la política turística determinó en gran medida el contenido de sus normas. Las normas turísticas no van a ser normas de largo alcance ni con contenidos sustantivos. Van a ser, básicamente, normas de fomento y normas de policía, amén de las imprescindibles de naturaleza organizativa. Es decir, normas destinadas expresamente a procurar el crecimiento de esta actividad y normas destinadas a asegurar los mínimos necesarios para su ejercicio, mínimos que sólo buscaban impedir actuaciones excesivamente comprometidas que perjudicasen el desarrollo del sector. Lógicamente, normas con este contenido habrían de ser reglamentarias.

Finalmente, no puede dejar de hacerse una breve referencia a las características del sistema de fuentes del régimen franquista, entre las que no era la menor la abundancia de reglamentos independientes, circunstancia coherente con los déficit democráticos del sistema ${ }^{38}$. Dada la naturaleza de este régimen nadie iba a reparar en la necesidad de fortalecer democráticamente la normativa turística.

Si la acumulación de causas podían hacer relativamente fácil de explicar el dominio de la norma reglamentaria durante el franquismo, no tan sencillo va a resultar explicar cómo esta situación se prolonga durante un largo periodo después de aprobada la Constitución. El reconocimiento constitucional de múltiples valores necesariamente afectados por la política turística, la diversificación de la potestad legislativa en la materia con la atribución de la competencia a unas Comunidades Autónomas deseosas de ejercer su potestad legislativa, las exigencias derivadas de la naturaleza democrática del nuevo orden jurídico-político o los cambios sociales, que forzaban necesariamente a un nuevo entendimiento de la política pública en relación con el turismo, eran circunstancias más que suficientes para pensar que el reglamento no tardaría en perder su protagonismo en la materia. Sin embargo, ello no fue así y ni siquiera la aludida aprobación de numerosas leyes generales de ordenación de la actividad turística permite afirmar con rotundidad que se ha producido la citada circunstancia.

Examinadas las causas que han podido motivar el dominio del reglamento en la ordenación del turismo, es momento para preguntarse por las consecuencias que este hecho ha podido tener.

La primera consecuencia natural, buscada y consciente es la de la flexibilidad del ordenamiento del sector turístico. Una flexibilidad que

38 Véase J.A. SANTAMaría PASTOR, «El sistema de fuentes del Derecho en...», ob. cit., pp. 535 y ss. 
DA-2001, núms. 259-260. JOSÉ TUDELA ARANDA. La ley y el reglamento en el Derecho del turis...

permitía acondicionar las normas a la muy mutable realidad económica, referencia inexcusable para el sector. Sin duda, existe una necesidad cierta en esos deseos de flexibilidad. Pero satisfacer esta comprensible demanda debería hacerse conciliándola con otros valores no menos significativos. Desde luego, no sin contemplar otro tipo de consideraciones, porque sino el resultado es la plena inseguridad jurídica, inseguridad que bien podría ser citada como segunda consecuencia de la masiva utilización de la norma reglamentaria ${ }^{39}$. Uno de los retos que deberá superar el naciente Derecho del turismo será sin duda el de dotar a este sector del ordenamiento de las imprescindibles exigencias de seguridad sin elaborar un corsé rígido que dificulte el normal desenvolvimiento de la actividad. Hay que llamar la atención sobre el hecho de que la inflación reglamentaria en este sector del ordenamiento ha llevado en ocasiones a una prevalencia de lo aplicativo frente a cualquier consideración normativa, incluso la reglamentaria. Normas perdidas en el marasmo de un ordenamiento subordinado a la eficacia en los resultados económicos no eran al final sino el reflejo de la dejación de lo jurídico en esta materia.

Una segunda consecuencia, si se quiere de mayor calado y significación, es la de haber contribuido decisivamente a la ausencia de una visión integral de la política turística. Puede decirse, y no faltaría razón, que el argumento habría de invertirse. Es decir, que ha sido la falta de esa visión general por parte del poder público la que provocó que no se aprobasen leyes en esta materia. Ello es rigurosamente cierto. Pero también lo es que esa actitud del poder público ha contribuido decisivamente a la visión que doctrinalmente, y no sólo desde una perspectiva estrictamente jurídica, se tiene del turismo. La ausencia de leyes generales ha dificultado de manera considerable la tarea de elaborar una perspectiva integral del sector. Es éste precisamente uno de los cometidos que cabe encomendar a la ley en las nuevas circunstancias sociales. La ley hoy, en sentido estricto nunca lo ha sido, no es sólo un conjunto de normas cuyo cumplimiento es exigible ante los tribunales. La ley es también un mandato político, la expresión de una voluntad, es la traducción jurídica del deseo políico de una sociedad interpretado por sus representantes. Por ello, la aprobación de una ley debiera tener un plus de significación irrenunciable. Ello implica tanto que el legislador debe tener buen cuidado de no dar rango de ley a aquello que no tenga el citado alcance políico como que la sociedad debe recuperar la percepción de la ley como documento político del más alto nivel. Sin duda, éste es un camino fundamental para su recuperación con todo su significado en nuestro ordenamiento. La elabora-

39 La doble consecuencia de la flexibilidad y de la inseguridad jurídica ya fue aludida por J.L. Villar PALASÍ, en el prólogo a la obra citada de J. FERNÁNDEZ ÁlvarEZ, Currso de Derecho administrativo turístico, p. III. 
ción de leyes para la regulación del sector turístico no debiera perder de vista esta perspectiva. En realidad, y como se examinará detenidamente en páginas posteriores, en esta función de la ley se encuentra la justificación última para legislar por ley el turismo.

La existencia de estas leyes evitará en gran medida la visión fragmentaria e insuficiente de la realidad turística, ayudará a equilibrar los numerosos y en ocasiones contrapuestos intereses en juego y, en fin, permitirá la elaboración de un cuerpo doctrinal que permita integrar las distintas lagunas y conflictos a los que una realidad tan rica y compleja como la estudiada está abocada ${ }^{40}$.

No sería justo decir que el dominio de la norma reglamentaria ha sido causa de la visión estrictamente economicista de la política turística. Como ya se ha indicado, es al revés. Ahora bien, hay que advertir cómo esta traducción jurídica de la visión que de esta materia ha tenido el poder público ha repercutido forzosamente en el olvido de valores colaterales a la actividad turística. En este punto, es preciso realizar una mención especial a la protección medioambiental. Aunque no pueda sino lamentarse, puede llegar a comprenderse quedada la naturaleza política del régimen anterior y las circunstancias sociales en el que el mismo se desenvolvió, la política turística de la época hiciese caso omiso de cualquier consideración medioambiental. Las consecuencias de esta opción son de sobra conocidas y no merece la pena extenderse sobre las mismas. Pero sí es preciso llamar la atención sobre los muchos años transcurridos entre la aprobación del texto fundamental y la aparición de las primeras referencias proteccionistas en relación con la política turística. Desde luego, la relevancia jurídica y social que este valor adquiere tras la aprobación de la Constitución va a ser una de las razones fundamentales para el desarrollo de una nueva política turística y de la correspondiente legislación ${ }^{41}$. Pues bien, fue necesario tener encima el fantasma de la recesión turística

40 Uno de los principales objetivos a satisfacer por el estudio jurídico del turismo es la formulación de los principios generales que se esconden detrás de la ya numerosa normativa turística al objeto de satisfacer las señaladas necesidades. Unos principios que no debieran atender exclusivamente a las normas turísticas sino que debieran ser formulados teniendo presentes aquellas ideas fuerza que rigen materias conexas y los valores sociales a los que deberá enfrentarse la aplicación de las normas turísticas.

41 En relación con este punto puede verse: F. LÓPEZ RAMÓN, «Contrastes y conexiones de la moderna consideración del medio ambiente en la legislación turística» en Régimen jurídico de los recursos utristicos, ob. cit., pp. 229-239; D. BLANQUER CIIADO, Derecho del turismo, ob. cit., pp. 159 206. En relación con aspectos concretos del medio ambiente, pueden citarse: J. Socías CAMACHO, «La incidencia del turismo en la ordenación del litoral (especial referencia al caso de las Islas Baleares)» en Régimen jurídico de los recursos turísticos, ob. cit., pp. 267-285; O. HERRÁlz SERRANO, «El aprovechamiento turistico de las vías pecuarias» en Régimen jurídico de los recursos turísticos, ob. cit., pp. 285-318, D. AZNAR JORDÁN, «Masas forestales, turismo y medio ambiente. Breve análisis sobre el uso recreativo de los montes» en Régimen jurídico de los recursos turisticos, ob. cit.; J. TUDELA ARANDA, "Turismo de montaña y estaciones de esquím en Régimen jurídico de los recursos uurísticos, ob. cit., pp. 483-517; J.M. ASPAS ASPAS, Los deportes de aventura. Consideraciones jutridicas sobre el turismo activo, Prames, 2000. 
para que se tomase conciencia de los peligros que para el turismo tenía continuar con una política irrespetuosa con los recursos naturales. Sin duda, estos riesgos se hubiesen visto disminuidos, y es sólo un ejemplo, desde la perspectiva ofrecida por un marco normativo apoyado en la ley y no en el reglamento.

Aunque las causas sean esencialmente comprensibles, no puede dejar de llamar la atención que la que ha sido pomposamente considerada primera industria nacional haya sido objeto de tan escasa y poco ambiciosa atención por parte del legislador. Ello no resulta extraño si se observan los muy significativos defectos de la estadística turística en nuestro País, la inexistencia de estudios turísticos acordes con la importancia del sector y la consecuente falta de formación de muchos profesionales del sector o las insuficiencias del tejido empresarial. Puede decirse sin riesgo a exageración que ni desde el poder público ni desde el sector privado se ha entendido necesario una visión rigurosa y profesional de la actividad turística. Los atractivos de nuestras costas y clima eran suficientes para paliar cualquier otro defecto y, por lo tanto, no era preciso más que esforzarse en establecer formas de fomento y las imprescindibles medidas de policía. Hoy esta visión esta teóricamente desechada. Aunque la inercia turística de nuestros recursos se sigue mostrando suficientemente poderosa, se es consciente de que el filón puede agotarse, se es consciente de que se debe y se pueden ofrecer modelos turísticos alternativos, que es necesario cambiar la cantidad por la calidad. Este tránsito en la percepción de las necesidades de la política turística se ha traducido en el mundo del Derecho en un volver la cabeza hacia la ley como instrumento primario no sólo para transformar su mundo normativo sino para proclamar a la sociedad el contenido del nuevo discurso político en la materia.

\section{LA IDONEIDAD DE LA LEY PARA REGULAR CON CARÁCTER GENERAL EL TURISMO}

\section{LOS PRESUPUESTOS DEL DEBATE}

No es habitual plantearse la pregunta de si la ley es instrumento idóneo para la ordenación de un determinado sector de la acción administrativa. Seguramente es una pregunta que debería haber sido habitual. Pero no lo ha sido. O no lo ha sido en la mayoría de los casos y, desde luego, no se ha planteado con la radicalidad con la que se ha hecho en relación con el turismo. En esta materia la pregunta de si debía existir una ley general que persiguiese la ordenación general del sector 
se presentaba como una de las cuestiones fundamentales a resolver. El hecho de que esta norma no existiese durante el régimen anterior y durante bastantes años de sistema democrático, hacía obligado plantear el interrogante. Más si no se olvida la brillante evolución del sector.

Podría pensarse que la dificultad de definir la materia turística era obstáculo suficiente como para pensar en la inviabilidad de la norma comentada y, por ende, dar respuesta al interrogante planteado. En efecto, la materia turística es etérea, compleja, cercana a lo inaprehensible. De hecho, no sólo su perspectiva jurídica habría sufrido por ello. Problemas similares se plantean para su estudio desde la economía o desde la sociología. Por otra parte, durante mucho tiempo no hubo una demanda social a favor de su aprobación ni, desde luego, el sector lo reclamaba. Todos los agentes implicados en la actividad turística estaban satisfechos con la situación de relajación y de flexibilidad provocada por el régimen jurídico en vigor. La aprobación de una ley podía traer a colación cuestiones que realmente no interesaban a nadie. El sector privado necesitaba de la agilidad e indefinición que le daba la normativa reglamentaria y el poder público se contentaba con los excelentes resultados económicos ${ }^{42}$.

Aun así, no podía considerarse como normal que pasados quince años desde la aprobación de la Constitución, ninguna Comunidad Autónoma hubiese aprobado ley alguna sobre la materia, excepto las obligadas por los principios constitucionales en relación con el Derecho sancionador. El turismo era una de las competencias asumidas con carácter exclusivo por todas las Comunidades Autónomas y desde la primigenia redacción de sus Estatutos ${ }^{43}$. No era normal que estos entes territoriales, deseosos de legislar por la innegable fuerza simbólica de esta potestad, no lo hubiesen hecho sobre una de las materias que más se prestaban a ello. En efecto. No era sólo el alcance teóricamente exclusivo de la competencia. La propia diversidad del sector en las distintas Comunidades Autónomas podía hacer pensar en la conveniencia de

42 El tercer agente implicado, el turista, no tenía protagonismo activo en la política turística durante esos años. Precisamente, el incremento de la conciencia social en relación con la protección de consumidores y usuarios y su natural repercusión en el ámbito turístico va a ser uno de los factores que obligue al poder a mirar su presencia en el sector de manera diferente y, a la postre, a pensas en la ley como instrumento adecuado para su regulación.

43 No se olvida la relatividad que tiene el carácter teóricamente exclusivo de las competencias autonómicas. Incluso puede decirse que el turismo es un claro ejemplo de la irrealidad de esa exclusividad al existir importantes títulos competenciales del Estado concurrentes sobre la materia como enseñanza, planificación económica o acción exterior. A pesar de ello, era el turismo una de las materias sobre las que con mayor claridad podía proyectarse el naciente poder autonómico. Sobre el reparto de competencias entre el Estado y las Comunidades Autónomas en materia turística puede verse: A. SALGADO CASTRO, «La distribución de competencias en materia de turismo», $o b$. cit; R. GARCíA MACHO, «La legislación turística: naturaleza jurídica...», pp. 25-30. 
DA-2001, núms. 259-260. JOSÉ TUDELA ARANDA. La ley y el reglamento en el Derecho del turis...

normativas distintas, respondiéndose así al sentido último de la autonomía. Sin embargo, hasta 1994, las Comunidades Autónomas van a seguir gestionando la actividad turística desde la aplicación supletoria de un Derecho estatal cada vez más obsoleto y confuso, con la sola ayuda de la limitada aprobación de normas reglamentarias propias en aquellas cuestiones que exigían de manera perentoria una nueva regulación. De acuerdo con este esquema, la política turística seguía respondiendo a las mismas premisas que la habían presidido hasta 1978. Gestión de un sector pujante y olvido de cualquier otra consideración.

La cuestión cambiará de manera radical con la aprobación de la Ley de turismo del País Vasco en 1994. Desde la aprobación de la misma, se abrió un camino que ha llevado a la aprobación por otras once Comunidades Autónomas de leyes similares, formando de esta manera ese significativo cuerpo legislativo que nunca había tenido la actividad turística. Ahora bien, hay que decir que en la Memoria que acompañaba el proyecto de ley remitido por el Gobierno vasco al Parlamento se hacía expresa referencia a las dudas que podía suscitar una norma de este tipo. Hasta tal punto era extraño al mundo del turismo la existencia de una ley de estas características ${ }^{44}$. Tras indicar que el legislador podía atender la regulación del fenómeno turístico siguiendo pautas puramente coyunturales, se señalaba en la Memoria que también era posible ejercer la potestad legislativa de manera ordenada, unitaria y sistemática, con un esquema previo y lógico, con un hilo conductor previamente establecido y en el que cada disposición se sustentase en el conjunto de disposiciones anteriores. Esta segunda opción es por la que optó el legislador vasco. Una opción arriesgada, que constituía una novedad radical en el Derecho del turismo y que abría una nueva etapa para el mismo.

También la doctrina se cuestionó rápidamente este tema en uno de los primeros trabajos aparecidos al hilo del nuevo Derecho que se perfilaba ${ }^{45}$. Como también sucedía en la Memoria de la Ley vasca, este primer estudio distinguía entre la idoneidad y la necesidad de regular el

44 En este sentido, puede leerse en el citado documento: "La propuesta que se formula tiene un cierto carácter de codificación de la normativa turística. ¿Es ello posible? ¿Qué ventajas reporta tal propuesta? Juega en contra de una regulación unitaria de lo turistico el propio carácter de la materia, un tanto evanescente, más sociológica o económica que jurídica. Igualmente, es un factor negativo el fuerte arraigo que tiene en la tradición jutridica el que en lo turístico, como en general en casi todo el Derecho de intervención económica, prevalezcan las normas reglamentarias y de naturaleza efimera... Admitiendo lo anterior, lo que sin duda puede discutirse es que la materia turistica esté condenada a vivir en el purgatorio de la normación fragmentaria, efimera e inferior. Efectivamente, el fenómeno turístico es relativamente joven, tiene raices sociológicas y su natutraleza es enormemente dinámica. Sin embargo, esta constatación no puede ineludiblemente conducir a constatar la imposibilidad de evitar la dispersión de la normativa turistica».

${ }^{45}$ Véase D. AZNAR JORDÁN, «Disposiciones normativas en el ámbito turístico» en Estudios sobre el régimen jurídico del turismo, ob. cit., pp. 169-211. 
turismo por ley. Si era sencillo concluir que las exigencias parciales de reserva de ley podían ser salvadas por leyes sectoriales y que, por ende, de esta exigencia no derivaba la necesidad de una ley general de ordenación del sector turístico, el problema se centraba en la discusión sobre la idoneidad de esta opción ${ }^{46}$.

El legislador vasco optó por una respuesta positiva porque consideró necesario dar un tratamiento unitario y sistemático a lo turístico, dotar a esta materia de un hilo conductor al que se pudiesen vincular las numerosas disposiciones inferiores. Lo sucedido en años posteriores podría llevar a considerar que fue una opción acertada. Desde estas páginas se avala, como inmediatamente se intentará demostrar, la tesis que en su momento siguió la Comunidad Autónoma vasca. Ahora bien, antes de entrar en el estudio de las consideraciones que intentan justificar esta afirmación es preciso realizar alguna reflexión más.

En primer lugar, hay que subrayar la oportunidad del cuestionamiento de la opción por la ley. Como señaló el profesor Lorenzo MAR'TíNRETORTILLO, es necesario ponderar el uso de la ley. La ley por sí sola no va a arreglar los problemas surgidos alrededor de una materia. La aprobación de leyes innecesarias, de leyes que no están destinadas a cumplirse, de leyes superficiales, lo único que provoca es la desconfianza y el alejamiento del ciudadano hacia esta fuente del Derecho ${ }^{47}$. El hecho de que este tipo de norma no existiese en relación con la actividad turística permitía y obligaba al poder público a afrontar la cuestión con mejores criterios no ya de técnica legislativa sino de oportunidad política ${ }^{48}$.

La última afirmación realizada nos lleva directamente a la otra cuestión que es preciso traer a colación. Se señalaba la oportunidad que ofrecía al legislador el hecho de enfrentarse a una materia que hasta la fecha no estaba regulada por ley. Esta circunstancia le dotaba de una li-

${ }^{46}$ Como se puede suponer, la necesidad del rango de ley para regular la materia turística se vinculaba a la necesidad de satisfacer las exigencias de reserva de ley en materias tales como Derecho sancionador o libertad de empresa. En la Memoria vasca se concluía que, aunque efectivamente pudiese ser necesaria la ley en determinados aspectos, ello no respondía a la pregunta fundamental hecha, ya que el problema podía ser resuelto mediante leyes sectoriales. Una respuesta similar da D. AZNAR JORDÁN, «Disposiciones normativas en el ámbito turístico" en Estudios sobre el régimen jurídico del turismo, ob. cit., pp. 208-209.

47 Véase, al respecto, L. MARTíN-RETORTILLO BAQUER, Lo puiblico y la acción administrativa: el fantasma de la corrupción en Luis Jordana de Pozas. Creador de Ciencia Administrativa, Universidad Complutense, pp. 86 y 87.

48 Aunque sería necesario un estudio pormenorizado para realizar consideraciones más rigurosas, no parece que el nivel de debate se haya mantenido en la mayoría de las Comunidades Autónomas que con posterioridad han aprobado una ley similar a la del País Vasco. Como ya se indicó en otro momento, tras la norma vasca comenzó a notarse las consecuencias del efecto dominó que se produce tras la aprobación de una ley innovadora por una Comunidad Autónoma. 
bertad inexistente en relación con la mayoría de las materias. Una libertad que debería ser utilizada tanto en el plano formal como en el de los contenidos para cuestionarse alguno de los elementos clásicos de la teoría de la ley. No son estas páginas en las que deba tratarse este tema. Sólo deberá aludirse a las cuestiones estrictamente necesarias para comprender adecuadamente la posición de que la ley en el Derecho del turismo. Pero no por ello debe dejar de aludirse al hecho de que la ley en el turismo deberá ir acompañada por la reivindicación general de esta fuente del Derecho en nuestro ordenamiento, por una reivindicación que pasa forzosamente por el examen crítico de mucho de sus postulados de presente.

\section{RAZONES QUE AVALAN LA IDONEIDAD DE LA LEY COMO NORMA GENERAL PARA LA REGULACIÓN DEL TURISMO}

Es hora de examinar detenidamente las razones que para el que escribe estas páginas avalan la opción por la utilización de la ley como instrumento normativo para regular de manera unitaria la actividad turística. Se trata de intentar demostrar que la ley puede ser un instrumento eficaz para mejorar el sector turístico, para lograr una mejor conciliación de los muy diferentes intereses que se dan cita en el mismo. Se trata de demostrar que como fuente del Derecho es la adecuada para abordar una tarea que se considera necesaria: la de abordar una regulación jurídica unitaria de un sector de particular importancia económica y social. Éste es uno de los objetivos fundamentales del presente trabajo. Desde la posición que se atribuya a la ley es desde la que deberá ser examinada la posición de las restantes fuentes del ordenamiento en esta materia. Hay que recordar, sin miedo a ser reiterativo, que la respuesta que se da en las páginas que siguen está vinculada a un determinado concepto de ley. Esa concepción de la ley seguirá acompañando estas palabras porque se considera de vital importancia para entender la distinta posición de las fuentes.

De acuerdo con lo señalado, no puede extrañar que se estime que el juicio de idoneidad sobre la ley como norma para regular el turismo, para hacerlo de forma general y pretendidamente unitaria debe estar vinculado estrechamente al grado de decisión política que se quiera atribuir a la aprobación de esa ley. Si existe un importante grado de decisión política en la vocación de regular la actividad turística, deberá acudirse a la ley. Si, por el contrario, se desea moverse en márgenes más estrictamente técnicos y no se desea hacer política en el sentido etimológico de la palabra, la ley sería innecesaria.

Ahora bien, la determinación de la decisión política que acompaña a la regulación del turismo debe responder a una premisa propia sin la 
que no es posible contestar a la pregunta anterior. La premisa, no podía ser otra, es la de si es posible abordar de forma unitaria y sistemática la regulación de una materia con características tan singulares como las que tiene el turismo. Fácilmente puede pensarse en su imposibilidad, al igual que mayoritariamente se ha considerado inabordable la elaboración de un código medioambiental. $\mathrm{O}$, bien, podría pensarse en el mantenimiento de una normativa fragmentaria y secundaria más acorde con esas circunstancias que hacen de la visión unitaria del turismo un ejercicio intelectual bastante complicado.

Es innegable que una de las características fundamentales de la actividad turística es la de su naturaleza poliédrica ${ }^{49}$. Es ésta una nota puesta de manifiesto unánimemente por la doctrina y fácilmente reconocible si se examina siquiera superficialmente el amplio abanico de normas consideradas turísticas. Junto a los conceptos más estrictamente turísticos como los de Administración turística, recursos turísticos o empresa turística, la normativa turística regula, y no precisamente de forma incidental, cuestiones medioambientales, urbanísticas, relativas al patrimonio histórico o a la ordenación del territorio, etc. Pues bien, esta diversidad es la que se presenta como un primer obstáculo para una posible ley de ordenación general de la materia. La respuesta ha de ser clara. Precisamente esa diversidad es argumento por sí solo suficiente para en la mayoría de las ocasiones hacer recomendable una regulación de ese estilo. Ahora bien, a esa conclusión se llega desde una premisa previa, no estrictamente jurídica, que no puede obviarse. Es ésta la prioridad que en la acción pública debe merecer la política turística. Si se entiende que ésta es una política secundaria, subordinada en cualquier caso a los intereses concurrentes con la misma, podría entonces pensarse que esa visión unitaria es innecesaria e imposible. Innecesaria porque no atendería a la satisfacción de ningún objetivo mayor. Imposible porque la primacía de los intereses sectoriales ahogaría cualquier intento de construcción unitaria. Pero es que el turismo no es, al menos para el Estado en su conjunto y para la mayoría de las Comunidades Autónomas, una política secundaria. El turismo es una política fundamental, instrumento principal de desarrollo económico y de ordenación territorial. El turismo se presenta, además, en su visión necesariamente renovada, como un agente relevante para la protección

49 En este sentido, el Informe de la ponencia especial del Senado sobre la situación del sector turístico, se expresaba diciendo que «el turismo debe ser concebido como una rcalidad poliedrica que ha de analizarse y abordarse desde perspectivas diversas que tengan presentes los aspectos medioambientales, sociales y culturales que le acompañan». Este carácter poliédrico no es ajeno a los problemas que plantea la definición de la actividad turística y, por tanto, del Derecho del turismo (vid. P. PY, Droit du tourisme, ob. cit., Pp. 6 y 7. 
medioambiental y la recuperación del patrimonio histórico. Por todo ello, no sólo es posible sino que es del todo necesario una visión integrada de esa política, una visión que permita poner la actividad turística al servicio de los diversos y muy significativos fines que puede cumplir y no sólo al servicio de las cifras económicas.

Precisamente, la regulación por ley de esta materia facilitará esta visión unitaria, obligando en muchos casos al legislador a hacerse este planteamiento ${ }^{50}$. Ello no implicará que la política turística sustituya la acción pública en los sectores indicados. Ello sólo significará que se entiende que el turismo es una actividad unitaria, con unos esquemas similares de funcionamiento en sus diversas manifestaciones y que en su desarrollo debe servir al cumplimiento de determinados valores y reglas sociales y no hacerse frente a ellos ${ }^{51}$. Para conseguir este objetivo, la existencia de una ley general de ordenación será una necesidad objetiva. De esta forma, puede decirse que la consideración en el presente de la política turística como una política principal conciliadora de intereses contrapuestos, pero unitaria, y la utilidad que para el reforzamiento de esta visión posee la aprobación de una ley general, convierte a éste en el primer argumento a favor de la regulación por ley general del turismo.

Determinado que no sólo es posible sino que es necesario una visión unitaria del fenómeno turístico, se está en condiciones de responder al quantum de decisión políticả hay en la regulación por ley general

50 Así, en la Exposición de Motivos de la Ley 11/1997, de 12 de diciembre, de la Comunidad Autónoma de Murcia, se indica que es objetivo de la Ley «hacer frente a la dispersión y adecuar el sector a las profundas transformaciones habidasw. Una declaración de contenido similar puede leerse en la Exposición de Motivos de la Ley 12/1999, de 15 de diciembre, de turismo de Andalucía.

51 Una de las notas inherentes a la acción turística es la tensión que siempre existirá entre su práctica y la preservación de los recursos que la originan. Hay turismo porque hay recursos turísticos. Pero el éxito de esos recursos como reclamo turístico puede traer como consecuencia, paradójicamente, la muerte del recurso y, por ende, el fin del turismo. Especialmente intenso en relación con los valores medioambientales, este conflicto no deja de ser significativo en otras materias como el patrimonio histórico. Si tradicionalmente la visión puramente economicista ha impuesto una política de ojos cerrados ante el acoso y derribo sufrido por determinadas recursos naturales o culturales, en la actualidad, al menos teóricamente, las tornas han cambiado y la prioridad se otorga a la conservación. Pero la idea clave para entender la nueva política turística y el papel que en ella le corresponde al poder público está en comprender que el turismo no tiene por qué necesariamente ser un enemigo del medio ambiente o del patrimonio histórico. Por el contrario, una gestión acertada de la política turística es aquella que sepa convertir al turismo en el primer protector y potenciador de los valores culturales y medioambientales. Sencillamente, porque si se quiere un turismo de calidad y constante en el tiempo y en el territorio, se requiere no ya de su respeto por los valores citados sino del descubrimiento de nuevos valores para generalizar las ventajas económicas asociadas al turismo. En relación con el concepto de recurso turístico, puede verse J. TUDELA ARANDA, «El significado y función de los recursos turísticos en la nueva legislación turística» en Régimen juridico de los recursos turísticos, ob. cit., pp. 201-228. 
del turismo y, en consecuencia, saber si se está ante un argumento a favor de la oportunidad de utilizar la ley para regular el turismo. ¿Existe decisión política al establecer las que han de ser reglas generales de la ordenación de ese sector? ¿Hasta qué punto puede hablarse de política en una normativa que debe ser eminentemente práctica y coyuntural? No es difícil intuir que desde estas líneas se va a estimar que es precisamente el alto grado de decisión política que en la actualidad acompaña al turismo lo que determina que necesariamente su regulación haya de ser realizada por ley.

Primeramente habrá que justificar el grado de decisión política que se vincula al turismo. Es ésta una cuestión de especial importancia porque se encuentra estrechamente ligada a los profundos cambios sufridos por la actividad turística en los últimos años. Si hasta principios de los años noventa la política turística siguió las pautas tradicionales, es decir, su encasillamiento en una visión estrictamente económica, la sombra de crisis aparecida durante esos años llevó al sector privado y al poder público a plantearse abiertamente el modelo seguido hasta entonces. El resultado fue contundente. Si la industria turística española quería mantener su privilegiada posición, estaba obligada a diseñar y seguir un modelo diferente, un modelo que, sin renunciar a las bases del exitoso esquema de sol y playa, conectase mejor con las nuevas demandas y valores sociales, permitienido diversificar la oferta y desestacionalizar la actividad ${ }^{52}$. La consecuencia es que a partir de la redacción del libro blanco sobre el sector y del posterior Plan FUTURES, lo que. no sin una cierta dosis de petulancia podría llamarse cultura turística, comenzará a cambiar significativamente. El poder público tomará conciencia de que ya no es posible construir un modelo turístico a espaldas de sus protagonistas, los turistas, cuando, además, éstos han dejado de ser sumisos usuarios para pasar a ser demandantes exigentes, claramente concienciados de los derechos que les asisten y de la clase de turismo que desean realizar o sacrificando al mismo los valores medioambientales. Términos como el de turismo sostenible comenzarán a hacerse habituales, siendo expresión de una clara conciencia sobre las nuevas pautas que debe seguir la política turística, una política que, por lo demás, va a estar por primera vez apoyada en estudios que abarcan campos diversos. Por otra parte, la oferta turística se diversificará considerablemente apareciendo nuevas fórmulas con necesidades muy diversas a las tradicionales. La aparición de ofertas turísticas distintas a la tradicional de sol y

52 A este objetivo respondió la elaboración del Libro Blanco sobre el sector, fruto de la colaboración entre el sector público y la iniciativa privada y que desembocó en la aprobación del citado Plan Marco de Competitividad del Turismo Español. 
playa, impulsará que en el turismo no se vea sólo una posible fuente de ingresos económicos sino, también, y en algunas Comunidades fundamentalmente, un instrumento, sino el único, para equilibrar el territorio y desarrollar nuevas y más exitosas políticas de desarrollo rural.

De esta forma, si hasta esos primeros años de los noventa podía pensarse en que la existencia o no de ley en materia turística era una cuestión discutible, hoy no parece posible seguir manteniendo esa posición. La política turística es en la actualidad lo suficientemente importante, afecta materias tan diversas y delicadas, que es inexcusable exigir su regulación por ley. Lo es tanto por razones de eficacia como por la necesaria vinculación de esa política con la ley como expresión del principio democrático. Aquello que hoy se entiende por política turística exige que el poder vincule su regulación a esos postulados del principio democrático que hoy por hoy, con todas las imperfecciones que se desee, sólo cumple la ley.

Es cierto que puede que no sea ésta la lectura que existe detrás de alguno de los textos aprobados desde entonces, que es cierto que todavía en cinco Comunidades Autónomas no existe esa ley. Pero ello no quita para que se siga postulando la presencia de la ley. Precisamente es en materias como la aquí estudiada donde de verdad tiene sentido el aprobar una ley. Como se ha recordado anteriormente, la aprobación de muchas leyes es un mero gesto para la galería. Leyes innecesarias, abocadas a esa tristeza singular de los textos normativos que nadie lee, que nacen con la certidumbre de su silencio ${ }^{53}$. Pero una ley que regule con carácter general la actividad turística, una ley que sepa dibujar una visión integral de la misma, una ley que sea equilibrio de intereses contrapuestos y guía en los inevitables conflictos, una ley que contribuya a obtener del turismo todas sus posibilidades, esa es una ley necesaria. Es cierto que su mera aprobación no será suficiente, que de casi nada servirá si no esta acompañada por la indubitada decisión del poder público de hacer realidad sus enunciados. Pero también lo es que es una condición casi obligada. Es difícil que el poder actúe desde una visión unitaria y el sector privado perciba esa coherencia si no hay detrás un texto legal que la avale. Ésta es precisamente una de las funciones de la ley. La ley, como se ha señalado, hay que entenderla como algo mucho más sugerente que el mero resultado de sumar sus preceptos. Hay que entender la ley como el grito de un legislador y de un gobierno, hay que

53 Por razones que pueden entenderse como natural, este tipo de leyes son especialmente abundantes en la Comunidades Autónomas. La generalización de la idea de que uno de los reflejos de la eficacia en el gobernar es la aprobación de muchas leyes o la voluntad de afirmar la autonomía por este procedimiento, ha provocado que se hayan regulado por ley materias que bien podrían haber sido objeto de regulación reglamentaria. 
entender la ley, pues, como la voluntad social expresada a través del cuerpo político de transformar un determinado sector de la vida social. Esta carga simbólica de la ley es fundamental. Parte del hacer político estará en saber transmitir esta idea. Sin duda, la cuestión fundamental será el lograr la legitimidad suficiente para que los ciudadanos presten atención a ese grito, para que los ciudadanos, con independencia de lo que piensen sobre su contenido concreto, tengan la certidumbre de que la norma se va a cumplir.

Pues bien, en materia turística, la aprobación de leyes generales del sector era especialmente propicia al cumplimiento de esa carga simbólica de la ley. La aprobación de esas leyes era uno de los mejores instrumentos de los que disponía el poder para decirle a la sociedad que la política turística debía cambiar y que los fundamentos que la sustentaban se iban a modificar radicalmente. En materia turística, la aprobación de una ley de las características citadas debe cumplir diversos objetivos. Objetivos que sólo pueden ligarse a la ley y que, en consecuencia, llevan a la conclusión de que si lo que desea es una modificación de las pautas turísticas existentes hasta el momento, que si lo que se desea es incorporar a la política turística los valores sociales hoy vigentes, entonces la ley es imprescindible.

La novedad que suponía la mera aprobación de una ley de estas características facilitaba la eficacia de su valor simbólico. Si hasta ahora se consideraba que la regulación fragmentaria y secundaria era suficiente, el hecho de aprobar una ley general debiera implicar algo más que una refundición y elevación de rango. La aprobación de una ley general en el sector debe ser la manifestación normativa de un cambio profundo en la manera de concebir el turismo. Un cambio que tendrá tres vectores. Por un lado, la concepción de la política turística como una política susceptible de tratamiento unitario y necesitada de coherencia y sistematicidad. Por otro, la incorporación de los valores que han acompañado el profundo cambio social acaecido en España en los últimos años y que indudablemente ha modificado los hábitos del turista. Finalmente, la conciencia de que el turismo no ha de tener como finalidad exclusiva el crecimiento económico sino que puede atender a otros fines de igual importancia y que en todo caso su capacidad de generar recursos deberá limitarse por su colisión con otros valores y fines. Por ello, la aprobación de la ley es necesariamente algo más que un estímulo al sector y una llamada a la conciencia social sobre la importancia del turismo ${ }^{54}$. Desde luego, también es eso. Pero en este caso lo es diciendo que la

54 En este sentido se expresa el legislador castellano-leones en la Exposición de Motivos de la Ley 10/1997, de 19 de diciembre, de la Comunidad Autónoma de Castilla y León, de turismo. 
DA-2001, núms. 259-260. JOSÉ TUDELA ARANDA. La ley y el reglamento en el Derecho del turis...

concepción sobre los argumentos que tradicionalmente sostenían al sector han cambiado. La aprobación de la ley no es sólo una llamada al sector y a la conciencia social. Necesariamente debe ser también algo más que una llamada de atención a todas las administraciones públicas implicadas para que desarrollen el nuevo modelo. El hecho de ser las primeras normas generales sobre el sector supone un plus irrenunciable para el legislador. En este punto, se pone de manifiesto la extraordinaria importancia que para una correcta política legislativa posee que el legislador tenga claramente definidos los objetivos que se desea alcanzar con la aprobación del texto legal, el para qué se legisla. Y como el legislador se confunde en gran medida con el Gobierno, es a éste a quien le corresponde poseer esa claridad cuando plantee al Parlamento su propuesta. Al poder legislativo, más bien, le correspondería controlar la virtualidad de los argumentos gubernamentales, introduciendo, en su caso, las correcciones necesarias. La aprobación de estas primeras leyes turísticas hacía inexcusable un debate con detenimiento de estas características, un debate que los modos tradicionales de la forma parlamentaria hoy sólo hacen parcialmente posible.

En este particular radica la importancia del hecho de que doce Comunidades Autónomas hayan aprobado en menos de seis años leyes generales ordenando el sector e incorporando, con mayor o menor fortuna, las nuevas pautas unánimemente predicadas en torno a la actividad turística. La lectura obligada que parece deducirse de este hecho es que la conciencia sobre los cambios acaecidos en el sector es generalizada. Detrás de su aprobación, y desde luego en ocasiones de manera más inconsciente que consciente, está el comienzo de una nueva etapa de la actividad turística, de una etapa que en esta ocasión y, por primera vez, va a ir acompañada del Derecho como instrumento para su articulación. La eficacia de las leyes aprobadas variará, en ocasiones será claramente menor. Pero, desde luego, no se podrá prescindir de su significado y, en cualquier caso, allí estará el texto aprobado para que en algún momento se reclame su vigencia y el valor de los principios que incorpora ${ }^{55}$.

Se ha querido demostrar que la fuerte vinculación que en el presente posee el turismo con la política hace necesario que la ley sea su instrumento normativo de ordenación y que lo haga desde una pers-

Desde luego, es un ejercicio necesario y de gran interés examinar la repercusión que la aprobación de esas leyes ha podido tener sobre el turismo en cada una de esas Comunidades Autónomas. Seguramente, los resultados demostrarían que en no pocas de ellas no se ha producido la transformación anunciada, incluso que no hay siquiera indicios de que ello se produzca. Pero esto no quita valor a lo dicho sobre el significado de su aprobación y los objetivos que la debían acompañar. Esto, más bien, nos trasladaría a las insuficiencias que la ley tiene en nuestro ordenamiento y en la conciencia política y social. 
pectiva integral de la política turística. Hay un último argumento al que es necesario aludir aunque sea común a cualquier ley que pretenda la regulación integral de un sector. Es el de la necesidad de que las leyes determinen el quantum de público que se considera preciso en la ordenación y gestión de la materia en cuestión. La división radical sobre público y privado es hoy difícil de sostener y así lo pone de manifiesto con claridad el propio Derecho del turismo, manifestación jurídica en la que la presencia simultánea del Derecho público y del Derecho privado es tan antigua como su propio origen ${ }^{56}$. La ley deberá incidir sobre esta cuestión. Pero lo que deberá decidir es algo más importante. Lo que la ley deberá decidir es cuál es el grado de decisión pública que debe existir en la materia objeto de regulación. Es éste un punto especialmente significativo que no debiera improvisarse. Debiera ser objeto de una reflexión previa que, lógicamente, se traduciría a lo largo de los distintos preceptos de la norma.

Finalmente, y en relación con esta perspectiva, hay que decir que la aprobación de la ley debería traer consigo la articulación de las formas necesarias para un correcto control político de su aplicación, para una adecuada evaluación del grado de cumplimiento de sus objetivos. No se desconoce que es ésta una cuestión lejana de la práctica de nuestro sistema y sólo predicada por algún manual de técnica legislativa. Pero que esto sea así en la actualidad para nada significa que deba seguir siendo así y que no sea una situación modificable. Precisamente, las circunstancias que acompañaban la aprobación de las recientes leyes turísticas, hacían posible haberse planteado esta cuestión. Hay que subrayar que no se trata de un prurito perfeccionista de los defensores de una más depurada técnica legislativa. Por el contrario, se trata de una cuestión de gran contenido político. En efecto, en la evaluación de la aplicación de la ley es al Parlamento al que debiera corresponder una posición principal. Se trataría, básicamente, de un juicio político sobre una cuestión política, sobre la capacidad del Gobierno para llevar a la práctica los mandatos contenidos en el texto legal. Sin duda, ello repercutiría muy beneficiosamente en la ley como instrumento jurídico. Un control cierto de su cumplimiento evitaría textos innecesarios o imposibles e incrementaría la conciencia social sobre el mismo. Pero, ante todo, sería un cambio significativo en las relaciones entre el Gobierno y el Parlamento y una distinta manera de proceder ante la forma de producción de las leyes. Ninguna de las leyes turísticas aprobadas hasta la fecha han previsto esta cuestión. Ha sido uno de los errores manifiestos de esta política legislativa. Un error comprensible desde la falta de refle-

${ }^{56}$ En este sentido puede verse D. BLANQUer CrIADO, Derecho del turismo, ob. cit., pp. 26-30. 
DA-2001, núms. 259-260. JOSÉ TUDELA ARANDA. La ley y el reglamento en el Derecho del turis...

xión general que acompaña a la tarea legislativa. Pero es una cuestión, precisamente por su naturaleza eminentemente política, sólo planteable desde las leyes ${ }^{57}$. Por eso, porque se predica como indispensable para un correcto desarrollo de la política turística, es por lo que se estima que es un argumento añadido a favor de que sea la ley el instrumento utilizado para regular el turismo.

Existe un último argumento a favor de acudir a la ley como norma general de ordenación de la actividad turística. Último pero bien podría ser primero. Primero sería, desde luego, si el orden se estableciese sobre lo hasta ahora mayoritariamente planteado por la doctrina. Se trata, claro esta, de la necesidad de satisfacer el principio de legalidad y las exigencias derivadas de la reserva de ley en determinadas materias íntimamente vinculadas con la actividad turística. Una ley general del sector turístico permitiría regular con precisión el ámbito sancionador y, simultáneamente, cubrir de la forma que se estimase precisa las necesidades de la reserva de ley establecida por la Constitución para materias tales como la libertad de empresa, propiedad, consumidores y usuarios, etc. La ley no necesitaría regular detenidamente estas cuestiones. Pero podría hacerlo en forma suficiente como para eliminar cualquier duda en relación con la eventual regulación reglamentaria. De esta forma, se resolvería la muy fundada incertidumbre que en relación con su legalidad plantean muchos de los reglamentos hasta la fecha vigentes en la materia. Es éste un argumento cercano a la necesidad. Pero la conveniencia de eliminar dudas innecesarias, de reforzar la seguridad jurídica nos habla también de oportunidad. Una oportunidad que debiera tener como límite el no confundir la ley con un receptor universal, de forma que todo lo que tradicionalmente ha estado regulado por normas reglamentarias pasase ahora a incorporarse al texto legal, desvirtuando seriamente su significado y dificultando la consecución de alguno de los objetivos anteriormente predicado para la ley.

Por todo lo señalado, se considera que la aprobación de una ley general de ordenación del sector turístico no es responder a la moda o a las necesidades legislativas de todo Gobierno que se precie. Es satisfacer necesidades objetivas de un sector fundamental de nuestra economía que se encuentra en profunda transformación y que por primera vez en su ya no tan corta historia ha acudido al Derecho en busca de respuestas sustantivas y no meramente sancionadoras $u$ organizativas.

57 Evidentemente que podría hacerse una reflexión paralela en relación con los reglamentos. Pero en este caso la perspectiva es necesariamente otra. El reglamento estará directamente vinculado a la efectividad de una política establecida en una ley. La mera aprobación de un reglamento es un primer paso cierto en el cumplimiento de lo dispuesto en la ley. Se trata, pues, de un nivel forzosamente inferior, con una naturaleza eminentemente técnica, sin que ello suponga obviar sus notas políticas que, evidentemente, también posee. 


\section{ALGUNA REFLEXIÓN A LA LUZ Y A LA SOMBRA DE LAS LEYES APROBADAS}

No puede extrañar que tras la aprobación en 1994 de la ley del País Vasco, la mayoría de las Comunidades Autónomas siguiese su ejemplo, desechando el otro modelo que el propio ejecutivo vasco planteaba como posible para acometer la regulación del sector turístico ${ }^{58}$. Un análisis de las materias en ellas reguladas da cuenta fehaciente de la importancia de estos textos y de los amplios vínculos que se establecen alrededor de la política turística. Medio ambiente, patrimonio histórico, régimen jurídico de las distintas empresas turísticas, régimen sancionador, colaboración interadministrativa, recursos turísticos, municipio turístico, planificación y relación Derecho urbanístico y ordenación del territorio, protección del turista como consumidor y usuario, son materias de regulación recurrente ${ }^{59}$. La conciencia adquirida sobre la imposibilidad de contemplar el turismo como un fenómeno aislado y la consecuente toma de conciencia sobre la necesidad de regularlo alrededor de unos principios esenciales que vertebrasen tanto la actuación de los particulares como de los poderes públicos, ha sido una de las causas que provocaron que se siguiese el camino vasco. Mas hay otras que deben ser enunciadas brevemente.

Referirse a estas causas es en gran medida reiterar los argumentos dados a favor de la ley como norma reguladora del sector. Evidentemente, la aprobación de la ley del País Vasco supone por sí sola un argumento importante para que otras Comunidades Autónomas aprueben leyes similares. La experiencia del Estado autonómico demuestra que una vez aprobada una ley sobre una materia por una Comunidad Autónoma, se abre un proceso en el resto de Comunidades, que puede ser más o menos intenso, pero que lleva a la aprobación de leyes similares, también por el contenido, en otras Comunidades. Este efecto al que ya se ha hecho referencia en estas páginas como efecto dominó ha tenido lugar en relación con el turismo. Pero limitar la explicación de que otras doce Comunidades Autónomas hayan aprobado leyes sobre esta materia y que al menos dos más se encuentren elaborando este texto a la pura mimesis con la experiencia vasca, sería insuficiente. Esta circunstancia también se explica en la toma de conciencia sobre la necesidad de paliar el déficit democrático que acusaba una legislación que cada vez era

Junto a las doce Comunidades Autónomas ya citadas en este trabajo que han aprobado leyes generales de ordenación del sector turístico, puede decirse que al menos en otras dos, Aragón y Navarra, se ha planteado públicamente por sus Gobiernos su próxima elaboración.

59 En relación con este punto puede verse D. AZNAR JORDÁN, «Disposiciones normativas en el ámbito turístico en Estudios sobre el régimen jurídico del turismo, ob. cit., pp. 188 y ss. 
DA-2001, núms. 259-260. JOSÉ TUDELA ARANDA. La ley y el reglamento en el Derecho del turis...

más compleja y afectaba a un mayor número de intereses; en la necesidad de resolver los problemas de legalidad e inseguridad jurídica provocados por el carácter mayoritariamente reglamentario de las normas turísticas ${ }^{60}$; en la importancia económica y social del sector, importancia creciente dada la incorporación de nuevos valores y funciones; $\mathrm{o}$, finalmente, la consideración de que era necesaria una visión integral de la política turística y que la aprobación de una ley general era un paso imprescindible para la consecución de este objetivo.

Son, como fácilmente puede entenderse, razones suficientes para comprender el profundo cambio habido en apenas cinco años en las fuentes del Derecho del turismo. De hecho, hay que reiterar una vez más, que lo único extraño es que las Comunidades Autónomas, tan deseosas de legislar, no lo hubiesen hecho antes en una materia que se prestaba abiertamente a ello. Explicado el proceso habría que examinar la eficacia de estas normas. Hoy es pronto para un examen que se entiende necesario y esclarecedor no sólo sobre la eficacia de las leyes turísticas sino sobre los hábitos legislativos del Estado autonómico. Pero si no se pueden realizar afirmaciones contundentes, sí parece posible realizar alguna consideración general. Así, se puede pensar que la generalización de la ordenación por ley de la actividad turística ha contribuido al nacimiento de una visión integral de la política turística y a la incorporación a la misma de nuevos valores y funciones. Especialmente notable sería el nuevo marco de relaciones que esta legislación habría abierto entre el turismo y el medio ambiente y la visión del turismo como elemento fundamental para el desarrollo rural y la ordenación del territorio. Hay que subrayar que la incorporación de esta función a la política turística da al turismo una riqueza añadida singular. En efecto, en Comunidades Autónomas en donde tradicionalmente el turismo, por sus cifras, ocupaba un lugar secundario, va a pasar a tener una posición especial porque en ellas lo necesario es la introducción de políticas que permitan corregir la angustiosa situación del mundo rural ${ }^{61}$. Por otro lado, la unánime incorporación a los textos legales de la consideración de la protección medioambiental como el primer límite a la actividad turística, necesariamente ha calado en la práctica turística fortaleciendo lo que era una conciencia incipiente. Es más, en algunos textos el legislador ha sabido incorporar la percepción de que al igual que sucede con el patrimonio histórico, la misma necesidad de generar recursos turísticos debía convertirse en un mandato proteccionista, dado el alto atractivo que como recurso turístico posee el medio ambiente.

${ }^{60}$ R. GaRCía MACHO, «La legislación turística: naturaleza jurídica; relaciones entre Derecho estatal, autonómico y local» en Lecciones de Derecho del turismo, ob. cit., p. 31.

${ }^{61}$ Esta función de la actividad turística ha sido claramente percibida por la Unión Europea que ha dedicado importantes programas y cuantiosos fondos a su desarrollo. Los cambios de valores y gustos en la sociedad han permitido el desarrollo de una oferta turística en el mundo rural que se percibe como imprescindible para el mantenimiento de la población en este medio. 
Junto a esta visión positiva, que podría extenderse a otras consideraciones de semejante tenor, habría que aludir a la principal consideración negativa que se percibe de este proceso. Una primera aproximación a lo realizado tras su aprobación por las correspondientes Comunidades Autónomas plantea la seria duda de su muy escaso desarrollo reglamentario. No hay reglamentos ejecutivos y apenas hay normas reglamentarias dedicadas a desarrollar los aspectos esenciales de esas normas. Tampoco se han puesto en marcha los distintos modelos de planificación en ellas previstos. Es cierto que el tiempo transcurrido no es excesivo y que se necesita de un examen más detallado. Pero no parece demasiado temeraria la presunción de que si bien el legislador tenía relativamente claros los grandes principios que debían presidir la política turística, los ejecutivos, a la hora de aplicarlos, se han encontrado de frente con todos los problemas que se derivan de un sector dominado por una inercia antigua y en el que los intereses son demasiados y demasiados complejos como para que los grandes cambios puedan producirse de la noche a la mañana por la sola aprobación de la ley.

Puede que en alguna Comunidad no exista una voluntad real de modificar drásticamente los principios tradicionales de la política turística. Pero en la mayoría sí existe esa voluntad plasmada en la correspondiente ley. Por ello, las insuficiencias en la aplicación de la ley no deben servir de argumento contrario a la utilización de esta fuente del Derecho. La ley es el primero de los argumentos con los que ha de contar el ejecutivo para hacer realidad el nuevo modelo turístico. Evidentemente, ya se ha dicho, por sí solo no será suficiente. Pero sí es condición imprescindible. La aprobación de una ley de estas características es la mejor manera que tiene el poder público de expresar su voluntad de transformar la política turística. Ahora bien, aprobada esa norma resta lo más complicado. Esa es tarea del ejecutivo. Pero tarea del legislativo será controlar el proceso y comprobar que lo aprobado en la ley no queda en una mera declaración de intenciones, comprobar que ese proceso de transformación se acomete y se hace desde los postulados planteados en la ley.

\section{LA POTESTAD REGLAMENTARIA EN EL ACTUAL DERECHO DEL TURISMO. ALGUNAS CUESTIONES CONTROVERTIDAS}

\section{EL ÁMBITO NATURAL DEL REGLAMENTO EN LA ORDENACIÓN DEL TURISMO. LA COLABORACIÓN LEY/REGLAMENTO}

La nueva posición de la ley en el Derecho del turismo obliga a cuestionarse sobre el papel que en la actualidad corresponde en ese Derecho 
a la norma reglamentaria. Si la generalizada aprobación de leyes turísticas continúa la tradición de una profunda intervención administrativa en esta materia ${ }^{62}$, no deja de suponer una significativa modificación de lo que habían sido los supuestos de esa intervención. Desde luego, no parece posible valorar de igual manera el papel del reglamento en el turismo antes y después del proceso iniciado por la Ley vasca de 1994. El reglamento ha dejado de ser la norma de referencia y su posición comienza a asemejarse más a la propia de cualquier otra área de la intervención administrativa. La ley ha venido a establecer principios, funciones y conceptos que deben regir el nuevo Derecho del turismo como respuesta a la necesidad de cambio del sector. La ley, también, ha venido a fijar aquellas materias que se reserva a su regulación, delimitando de esta forma con mayor claridad, aunque no sin problemas, como se verá, el ámbito de la norma reglamentaria.

Ahora bien, ello en absoluto ha de entenderse como la práctica desaparición del reglamento en la normativa turística. Por tradición, por la complejidad intrínseca al fenómeno turístico, el reglamento tendrá en el turismo, como en todas las facetas del Derecho administrativo económico un papel de singular importancia. La presencia de la ley lo que va a hacer es subordinarlo a una concepción general de la actividad turística. Algo que, por lo demás, debería haber sucedido hace muchos años.

La presencia del reglamento en el Derecho del turismo debe ayudar a eliminar de la ley todas aquellas normas que no posean significado suficiente como para ser incorporadas al texto que ha de contener los principios rectores de la disciplina. La ley debe prescindir de todas aquellas cuestiones que por su concreción o carácter eminentemente técnico sólo acaban ocultando las cuestiones esenciales en ella reguladas. Por ello, la reivindicación de un papel protagonista para el reglamento en el turismo es también una forma de reivindicar la ley. Sólo con unos buenos y eficaces reglamentos será posible pensar en leyes con las características que deben acompañar a estos textos.

De esta manera, la cuestión fundamental se centrará en la colaboración entre la ley y el reglamento. En este punto es preciso señalar la necesidad de que el legislador contemple el Derecho del turismo como una unidad desde el primer momento. El hecho de ser un sector del ordenamiento en fase de formación hace más sencilla esa visión global. Antes de aprobarse una ley general de la ordenación del sector, el legislador debería determinar con precisión el ámbito de la ley y las normas

62 Domingo AZNAR recuerda cómo la consecuencia inevitable de esa intervención administrativa será la profusión de normas en la materia, D. AZNAR JORDAN, «Disposiciones normativas en el ámbito turístico» en Estudios sobre el régimen juridico del turismo, ob. cit., p. 173. 
reglamentarias necesarias para su desarrollo. De esta forma, la ley podría cubrir oportunamente los ámbitos de reserva de ley que le correspondan y podrían hacerse las necesarias llamadas al desarrollo reglamentario. En el Derecho del turismo se antoja especialmente necesaria la consecución de una adecuada colaboración entre la ley y la norma reglamentaria. Hay coincidencia en estimar que la eficacia de este Derecho pasa porque la cada vez mayor presencia de la ley se combine con un juego flexible de remisiones al reglamento ${ }^{63}$. Es preciso encontrar fórmulas que doten de agilidad y flexibilidad a esta colaboración, haciendo innecesarios tanto los textos legales llenos de preceptos excesivamente técnicos como las modificaciones frecuentes de esos textos para acomodarlos a una realidad que cambia con extraordinaria rapidez.

Es en este punto donde cabe introducir una referencia al papel que al reglamento independiente le pueda corresponder en este nuevo Derecho del turismo presidido por la ley. Se señaló en su momento que el Derecho del turismo era uno de los sectores normativos seguramente con mayor presencia de reglamentos independientes. Reglamentos que habían sobrevivido sobradamente al régimen anterior y que escasamente habían sido cuestionados. Ahora bien, esta situación cambia con la generalización de la aprobación de las leyes comentadas. Reafirmada expresamente la voluntad dél legislador de regular por ley y con carácter general la actividad turística, ¿hay margen para la existencia del reglamento independiente en el Derecho del turismo? En su caso, ¿qué materias podría regular? ¿Con qué alcance? Con la evolución seguida por la ley en el Derecho del turismo y con el convencimiento de la necesidad de la presencia de esta norma para la regulación de sector tan complejo, no parece que pueda darse a las preguntas planteadas respuesta diferente a la que se daría en relación con la ordenación de otra materia. La ausencia de ley, el convencimiento sobre su inidoneidad para regular el turismo, podía obligar a pensar en planteamientos diferentes. En la actualidad, no. Cuestión distinta es que hayan de revisarse algunos de los planteamientos clásicos en relación con la reserva de ley y el reglamento independiente. Pero ésta no será una peculiaridad del Derecho del turismo. Así, el margen para el reglamento independiente en el Derecho del turismo es hoy necesariamente escaso. Es más, la aprobación de las leyes citadas pone más en evidencia que nunca los numerosos ejemplos aún existentes de este tipo de normas en el Derecho del turismo.

Ahora bien, cuestión necesariamente diferente es la referida al alcance que el reglamento puede tener en el Derecho del turismo. El reglamento en el Derecho del turismo deberá seguir siendo una norma

63 Vid. J. Socfas CAMACHO, «Evolución de la legislación turística en las Islas Baleares», $R A r A P \mathrm{n}^{\circ} 13$, pp. $230-231$. 
DA-2001, núms. 259-260. JOSÉ TUDELA ARANDA. La ley y el reglamento en el Derecho del turis...

fundamental. La regulación de muchas de las materias turísticas deberá realizarse esencialmente por reglamento, dejando a la ley sólo el establecimiento de los principios esenciales y el marco de relaciones con las restantes materias del sector. Es cierto que ante las dudas suscitadas por el principio de reserva de ley bien podría plantearse que al margen de la ley general otras cuestiones se regulasen por leyes más específicas. Pero sin desechar totalmente esta posibilidad, hay que señalar que mayoritariamente será en el reglamento donde tenga cabida su regulación. Puede que desde una concepción clásica esos reglamentos fuesen más allá de lo que se entiende por un reglamento ejecutivo. Pero el Derecho del turismo, seguramente como otras facetas de la acción administrativa, especialmente en el Derecho económico, exigen de una visión renovada de la relación entre la ley y el reglamento, de una visión que permita establecer una relación más ágil entre las dos normas, reservando para la ley el espacio de definición política, de concreción de unos valores y principios que, lógicamente, será más resistente al cambio y reservando para el reglamento los aspectos técnicos, la regulación particularizada, esa regulación que estará mucho más sometida a modificaciones. Completar este proceso exigirá establecer un adecuado sistema de control. Control jurídico pero también control político del cumplimiento del modelo que un día se estableció por ley.

De esta forma, puede concluirse diciendo que la aprobación de las leyes generales de turismo lo que ha provocado, fundamentalmente, es la regularización de la posición del reglamento en el Derecho del turismo. Muchas de las apreciaciones que se hacen en relación con el mismo serían ya válidas en otros sectores del ordenamiento. Como singularidad, la necesidad de reconocer a muchos de los reglamentos turísticos un contenido que en estrictos términos sobrepasaría a lo que se entiende por un reglamento ejecutivo.

\section{LA PROBLEMÁTICA RELACIONADA CON LA RESERVA DE LEY}

Con lo indicado en relación con la posición de la ley y el ámbito natural del reglamento en el Derecho del turismo, se han definido los aspectos esenciales de la problemática que el principio de reserva de ley puede plantear en el Derecho del turismo. Como se ha señalado, la mayoría de las materias que normalmente se engloban como normativa turística exigen de ley para su regulación e invalidan la presencia del reglamento independiente. Así sucede en las materias afectadas expresamente por la reserva de ley en la Constitución, que serían la mayoría. Y en aquellas en las que no existiese expresamente esta reserva la conclusión hoy tendría que ser similar. Desde luego, debería serlo en las Co- 
munidades Autónomas que han aprobado una ley general de turismo. No cabe pensar en la regulación por reglamento independiente de materias turísticas no previstas en esa ley. En aquellas Comunidades en las que esa ley no se ha aprobado, la gran vinculación de la nueva política turística con materias como los Derechos al medio ambiente o a la protección del patrimonio histórico o como la libertad de empresa, hacen difícil la legalidad de ese reglamento independiente. Y, desde luego, es totalmente impensable la presencia del reglamento independiente en el Derecho sancionador en materia turística ${ }^{64}$ así como en el terreno recién iniciado por la Comunidad Autónoma de las Islas Baleares de la fiscalidad turística.

Sin embargo, estas premisas están lejos de resolver todos los problemas. Fundamentalmente, porque la cuestión se planteará sobre el grado de concreción exigible a la ley para satisfacer la exigencia de reserva de ley. En efecto, el problema no es tanto determinar qué materias de las relacionadas con el Derecho del turismo se encuentran afectadas por el principio de reserva de ley, como el de precisar qué grado de regulación de las mismas exige este contenido en el texto legal.

El problema se plantea especialmente agudo en relación con la regulación de las empresas turísticas. Normalmente, la regulación por la normativa turística de este muy amplio elenco de empresas ${ }^{65}$ supone la introducción de requisitos específicos para el desarrollo de sus actividades, incluyéndose la exigencia de una licencia o autorización especial para el inicio de las mismas y la inscripción en un registro especial. En general, estos requisitos adicionales han venido estableciéndose en normativa reglamentaria sin que existiese una ley previa que les diese la más mínima cobertura. Sorprendentemente, esta situación no provocó una reacción jurisprudencial, cuando, al menos tras la aprobación de la Constitución, las dudas sobre la adecuación de estas normas a las previsiones constitucionalmente establecidas sobre la reserva de ley en relación con la libertad de empresa parecían más que fundadas ${ }^{66}$. Así, la

64 En este sentido, D. AZNAR JORDÁN, «Disposiciones normativas en el ámbito turístico» en Estudios sobre el régimen juridico del turismo, ob. cit., pp. 205-208; J.L. BLASCO DíAZ, «La disciplina turística: inspección y sanción» en Lecciones de Derecho del turismo, ob. cit., pp. 183-224.

${ }^{65} \mathrm{Ha}$ sido tradicional en nuestro Derecho establecer un concepto amplio de empresa turística. Así, además de las empresas que directamente se encuentran vinculadas a esta actividad, como las agencias de viaje o las empresas de hostelería en todas sus categorías, también se han incluido a las empresas de restauración, sin matiz alguno, balnearios, estaciones de esquí o, más recientemente, todas las relacionadas con el desarrollo de actividades en el mundo rural relacionadas con lo que viene denominándose turismo verde o rural. Un estudio pormenorizado de las distintas empresas que la legislación califica como turísticas puede verse en D. BLANQUER CrLADO, Derecho del turismo, ob. cit.

${ }^{66}$ Hay que recordar la muy escasa presencia en los tribunales de las cuestiones más controvertidas del Derecho del turismo. En relación con las dudas suscitadas por dos de las normas más interesantes del Derecho del turismo autonómico, los llamados Decretos "Cladera I" y «Cladera II", de las Islas Baleares, por su posible afección del principio de legalidad, puede verse, J.M. SOCÍAS CAMACHO, «La evolución de la legislación turística en las Islas Baleares", RarAP n n 13, 1998, pp.199-200. 
normativa completa sobre empresas como las agencias de viaje, los campings o las empresas de hostelería, se contenía en unas normas que aparecían en el ordenamiento como auténticos reglamentos independientes. Estas normas establecían un régimen especial para una categoría de empresas, separándolas de la normativa general. Nada de especial, salvo la ya aludida ausencia de ley que sirviese de cobertura.

Lógicamente, la existencia en la mayoría de las Comunidades Autónomas de leyes generales en la materia obliga a modificar el análisis. En todas las leyes aprobadas existe una regulación más o menos extensa de estas empresas, así como de las otras cuestiones que relacionadas con la actividad turística podrían plantear problemas en relación con la reserva de ley. De esta forma, al menos, ya existe cobertura legal. El problema deriva a intentar determinar qué grado de concreción tiene que tener la normativa contenida en la ley para satisfacer las exigencias constitucionales.

Desde luego, no será suficiente una mera alusión genérica. La ley deberá contener los principios esenciales de la regulación. Pero tampoco mucho más. En efecto, el principio de reserva de ley es una primera exigencia a satisfacer. Pero la normativa turística debe responder también a otras necesidades, entre las que no es la menor la eficacia. Y para que las normas turísticas sean eficaces es del todo necesario que se puedan modificar con prontitud, que con agilidad puedan responder a las circunstancias de su entorno, más cuando no puede olvidarse la rapidez de los cambios del mismo. Por otro lado, la ley, si quiere ocupar el lugar que le corresponde no ya entre las fuentes sino en la conciencia político y social, no puede acoger en su seno regulaciones exhaustivas, repletas de tecnicismos, de muy difícil comprensión para la mayoría de la ciudadanía que es su destinataria. La ley debe contener y establecer las premisas esenciales, de forma que su modificación sólo sea precisa cuando cambie el enfoque político que la respaldó cuando su aprobación o en el supuesto de que los cambios sociales sean tales que sea imprescindible una nueva ley, al no ser suficiente la modificación de la normativa secundaria.

Éste es el esquema que explica la importancia de la llamada a la colaboración entre la ley y el reglamento en el Derecho del turismo. Una adecuada política legislativa debería contemplar, como ya se ha señalado, conjuntamente la ley que se va a aprobar y los reglamentos que van a ser necesarios para su desarrollo, de forma que la ley establezca de manera completa y razonada ese marco normativo, delimitando con precisión aquellas cuestiones que deberán ser reguladas por los reglamentos de desarrollo.

De esta forma, puede decirse que desde las premisas actualmente vigentes en nuestro sistema de fuentes del Derecho, en materia turística no es posible contemplar el reglamento independiente, al menos en las 
cuestiones más significativas relacionadas con la actividad turística ${ }^{67}$. Ahora bien, ello también significa la necesidad de, al menos en una materia como la turística, de reforzar la norma reglamentaria, de depurar al máximo la ley de normas cuyo acomodo natural es el reglamento y de no entender la reserva de ley como equivalente a la necesidad de una regulación por ley siquiera parcialmente completa de la materia en cuestión.

\section{A MODO DE CONCLUSIÓN}

El estudio de la ley y el reglamento como principales fuentes del Derecho del turismo exige la realización de alguna reflexión previa en relación con la teoría general de las normas citadas. Sin olvidar otras consideraciones de señalada importancia, cabe traer a estas líneas finales tres ideas que habrán de ser tenidas en cuenta a la hora de realizar su estudio en relación con la regulación de la actividad turística. Por un lado, es necesario recordar las dificultades, cada día mayores, que tiene la elaboración de una teoría general de la ley en nuestro ordenamiento, dificultades que repercutirán necesariamente en la indeterminación de conceptos como el de reserva de ley, de notable importancia en el Derecho del turismo. Por otro, la reivindicación de la naturaleza política de la ley, su comprensión como la traducción jurídica de la voluntad política de transformar un determinado sector. Finalmente, y en lo relativo al reglamento, su extraordinaria importancia en el Derecho administrativo económico y la necesidad de contemplar para el mismo nuevas formas de relación con la ley.

Ha sido sensación generalizada la de que el turismo y el Derecho eran dos mundos distantes. Ni la doctrina ni la jurisprudencia se habían ocupado tradicionalmente de una materia dominada aparentemente por un marasmo confuso e incoherente de normas reglamentarias cuyo contenido se limitaba a medidas organizativas, de fomento y de policía. Una situación que lejos de cambiar con el nuevo régimen político y la atribución de la competencia en materia turística a las Comunidades Autónomas, se mantiene durante largos años. Lejos de ser neutral, esta situación había contribuido poderosamente a la inseguridad jurídica del sector, al olvido de valores colaterales de extraordinaria importancia y a la inexistencia de una política turística integral.

Ante esta situación no podía dejar de plantearse la posibilidad de elaborar una ley general para regular la actividad turística. La novedad

${ }^{67}$ Ello supone, desde luego, la convicción de que la normativa turística en aquellas Comunidades Autónomas que no han aprobado una ley general de ordenación del turismo, roza en la mayoría de los casos la legalidad. 
DA-2001, núms. 259-260. JOSÉ TUDELA ARANDA. La ley y el reglamento en el Derecho del turis...

sería doble. Por un lado, se trataría de dar coherencia y unidad a una actividad que hasta entonces había sido contemplada no ya fragmentariamente sino única y exclusivamente desde la óptica reduccionista de su significado económico. Por otro, y en coherencia con la mayor ambición de la regulación, y frente a lo que era tradicional, se utilizaría la ley como instrumento normativo. El cambio de valores sociales, la mayor importancia adquirida por cuestiones como la protección medioambiental o la calidad de la oferta turística, no podían sino precipitar la elaboración de esa ley general. Y así sucedió en 1994, en el País Vasco, abriéndose un camino que desde entonces seguirían otras once Comunidades Autónomas. Un camino que planteó desde sus inicios una cuestión fundamental, la de la idoneidad de la ley como norma para regular la actividad turística.

Así, la cuestión más significativa a la que hay que enfrentarse a la hora de estudiar las fuentes del Derecho en el turismo es la de si la ley es realmente el instrumento adecuado para regular este sector de la economía o si, por el contrario, y salvando en otras leyes sectoriales las necesarias exigencias derivadas del principio de reserva de ley, era conveniente seguir manteniendo su regulación en la normativa secundaria. No se trata, como se observa, tanto de discernir sobre la necesidad jurídica de acudir a esa ley generalista como de evaluar su oportunidad. En este extremo es forzoso que vuelva a aparecer la naturaleza eminentemente política de la ley, incluso la necesidad de reforzar esta característica como su primera seña de identidad. Y es preciso volver a recordarlo porque la respuesta esta indisolublemente ligada a la convicción de que la regulación global de la actividad turística requiere de un previo enfoque político que determine prioridades en los objetivos a alcanzar, los límites necesarios del sector y la jerarquía imprescindible entre los distintos valores que pueden llegar a entrar en conflicto. Hoy ello es necesario para que la actividad turística se acerque más al deber ser y deje de ser un reino de taifas salvado por la generosidad de nuestra naturaleza. Es necesario entender de manera global el sector y para ello es necesario la existencia de una ley que de forma global lo regule. A este convencimiento parece responder la generalización de estas normas en las Comunidades Autónomas. Con ellas se abre una nueva etapa para la actividad turística en España. Una etapa en la que por primera vez el Derecho va a ser instrumento de referencia.

La afirmación de la ley no supone la reducción del reglamento a un papel marginal. Necesariamente, el reglamento habrá de seguir teniendo una importancia singular en la regulación del turismo. Ello será así por la naturaleza económica del turismo pero también por algunos rasgos propios de esta actividad que obligarán a descargar en los reglamentos un quantum muy significativo de normas. Entre la ley y el reglamento 
debe establecerse una relación ágil y compłementaria que permita a la ley preservar sus formas eminentemente políticas, salvando las exigencias necesarias de reserva de ley y a la Administración utilizar el reglamento como norma flexible, idónea para adaptarse a los numerosos y frecuentes cambios del sector y adecuada para regular aspectos fundamentalmente técnicos. 